\title{
Nuevas (y no tan nuevas) aportaciones al estudio de la batalla de Muret
}

\author{
New (and not so New) Contributions to the Study of the \\ Battle of Muret
}

\author{
Martín Alvira CABRER \\ Universidad Complutense de Madrid \\ malvira@ghis.ucm.es
}

\begin{abstract}
RESUMEN
Comentario y valoración de la bibliografía sobre la batalla de Muret (1213) publicada en la última década (2002-2012). Se comentan las ediciones de fuentes documentales y narrativas, los repertorios bibliográficos, los estudios sobre la memoria de la batalla en la época contemporánea y, más ampliamente, las contribuciones al conocimiento del contexto histórico (catarismo, Cruzada Albigense, reinado de Pedro el Católico). La atención se centra en los estudios de Historia Militar que han intentado esclarecer lo sucedido en el campo de batalla. En este ámbito específico de la guerra, el comentario de las aportaciones más recientes se complementa con el análisis de trabajos anteriores a 2002 en lengua inglesa, bien porque son inéditos y poco accesibles a los investigadores, bien porque merecen ser mejor ubicados en el panorama general de la historiografía de la batalla de Muret.
\end{abstract}

Palabras clave: Muret, batalla, historiografía, Siglo XIII, Pedro el Católico, Corona de Aragón, Historia Militar.

\begin{abstract}
An overview of the bibliography of the Battle of Muret (1213) published in the last decade (2002-2012). We discuss the edition of narrative and documentary sources, the bibliographical compilations, the memory of the battle in modern times and, more broadly, contributions to the knowledge of the historical context (Catharism, the Albigensian Crusade, the reign of Peter the Catholic). The focus is on studies of Military History that have attempted to clarify what happened on the battlefield. In this specific area of the warfare, comments on the most recent contributions are complemented by the analysis of works prior to 2002, especially in English, either because they are unpublished and hardly accessible to researchers, or because they deserve to be better placed in the whole historiography of the Battle of Muret.
\end{abstract}

Key words: Muret, Battle, Historiography, XIIIth Century, Peter the Catholic, Crown of Aragon, Military History. 
Desde hace más de un siglo, la historiografía contemporánea ha tratado de explicar lo que sucedió en la batalla de Muret y ha interpretado de diferentes formas sus consecuencias históricas. Aportaciones, en uno u otro ámbito, las ha habido casi siempre, pero en estas páginas nos centraremos en los trabajos aparecidos en la última década y en algunos anteriores no manejados o no explotados en su momento ${ }^{1}$.

Lo cierto es que las novedades recientes afectan casi más a los aledaños de Muret que a la propia batalla. Una de las grandes aportaciones de los últimos tiempos ha sido la edición de colecciones documentales relacionadas con el choque. En 2008, Laurent Macé publicó los catálogos de las actas de condes de Tolosa, entre las que figuran los documentos de Raimon VI y algunos dados por el rey Pedro el Católico o relacionados con la situación política previa a la batalla de Muret ${ }^{2}$. Un año más tarde, apareció una edición de los tratados y las negociaciones diplomáticas del condado de Barcelona y la Corona de Aragón con los poderes occitanos entre 1067 y 1213 . La obra fue dirigida por Maria Teresa Ferrer y Manuel Riu, si bien la responsabilidad de la documentación occitana, cuya parte final se refiere al reinado de Pedro el Católico, corresponde a Pere Benito ${ }^{3}$. Por último, las fuentes del monarca derrotado en la batalla de Muret vieron la luz en 2010 en una publicación accesible on line. Se recogen en este trabajo los documentos emitidos por la cancillería regia y los enviados a Pedro el Católico por otras instancias de poder. La edición documental se complementa con un repertorio de fuentes narrativas (siglos XIII-XV), otro de testimonios historiográficos (siglos XVI-XXI) y unos apéndices que incluyen, entre otras cosas, el itinerario real y el listado de participantes en la batalla de $1213^{4}$.

Quien quiera profundizar en la historia de este choque también cuenta con novedades interesantes en el ámbito de las fuentes narrativas. Gracias a la tesis del alemán Kay Wagner, hoy son fácilmente localizables las crónicas de la Cruzada Albigense que dan (o no) noticia de la batalla de Muret. El listado de textos fue presentado por este autor en el coloquio sobre la Cruzada celebrado en Carcassonne en 2002 ${ }^{5}$. En las actas de esta reunión también se habló de los problemas que presentan las fuentes de este conflicto y de las interpretaciones del mismo en las crónicas angevinas, la cronística castellano-leonesa y la versión del premostratense Robert d'Auxerre ${ }^{6}$. Se han estudiado igualmente los testimonios trovadorescos y analísticos de la Cruzada Albigense en comparación con los de otras "guerras santas" coetáneas (cruzadas

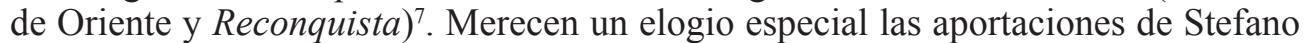
Maria Cingolani sobre las fuentes narrativas de la Corona de Aragón. Gracias a este especialista tenemos una idea mucho más clara de la génesis de la historiografía medieval catalano-aragonesa ${ }^{8}$, conocemos al detalle cómo y por qué escribió Bernat

${ }^{1}$ Este texto fué un encargo del "Anuario de Estudios Medievales" para un dossier sobre Muret luego cancelado. Bibliografía anterior o no citada en Alvira, El Jueves, 2002 (véase Macé, Muret, 2004).

${ }^{2}$ Macé, Catalogues, n 256-409, esp. 333, 336-338, 347, 407, 408 y 434.

${ }^{3}$ Ferrer y Riu (dirs.), Tractats, $\mathrm{n}^{\circ}$ 141-169.

${ }^{4}$ Alvira, Pedro el Católico, 2010.

5 Wagner, "Debellare", 2000; y Les sources, pp. 39-54.

${ }^{6}$ Aurell, Les sources, pp. 21-38; Moore, Les Albigeois, pp. 81-90; Baloup, La Croisade, pp. 91-107; y Cavazzocca-Mazzanti, La Croisade, pp. 55-69.

7 Alvira, Del "Sepulcro", pp. 187-229, esp. 209.

${ }^{8}$ Cingolani, La memòria, 2007. 
Desclot, tan decisivo en la conformación de la memoria catalano-aragonesa de la batalla de Muret $^{9}$ y comprendemos mucho mejor la versión de la derrota ofrecida por el hijo de Pedro el Católico en su Llibre dels fets $^{10}$. Más trascendentes, incluso, que estas contribuciones son las nuevas ediciones de textos históricos que Cingolani está publicando en la colección Monuments d'Història de la Corona d'Aragó, una iniciativa de enorme envergadura que está llamada a marcar un antes y un después en el devenir de los estudios sobre la Corona de Aragón medieval ${ }^{11}$.

El recuerdo de la batalla de Muret en la historiografía contemporánea ha recibido una atención relativamente importante en el seno, una vez más, de trabajos centrados en la Cruzada Albigense y la historia del catarismo. En el año 2006, el especialista italiano Marco Meschini coordinó un repertorio bibliográfico de la cruzada anticátara elaborado por un equipo internacional de investigadores vinculado al recientemente desaparecido Centre d'Études Cathares René Nelli de Carcassonne ${ }^{12}$. Al mismo tiempo, la memoria histórica y popular de Muret en la Francia de los siglos XIX y XX ha sido estudiada por Philippe Martel y René Soula, dos historiadores occitano-parlantes cuyas reflexiones son claves para comprender nuestra actual percepción de la historia plenomedieval occitana ${ }^{13}$. La evolución paralela de esta memoria histórica en la historiografía española, especialmente catalana, ha sido examinada recientemente al calor de estos estudios franceses ${ }^{14}$.

El conocimiento del contexto histórico en el que debe explicarse la batalla de $\mathrm{Mu}-$ ret ha experimentado una notable renovación en los últimos años. El clima religioso que envolvió el choque de 1213 sigue dando juego. Los debates actuales en torno a la interpretación del catarismo tienen un buen reflejo en el homenaje dedicado en 2005 a Jean Duvernoy, uno de los padres del estudio histórico del fenómeno cátaro, que falleció en $2010^{15}$. En el ámbito de la doctrina, la tesis doctoral de Pilar Jiménez constituye una aportación novedosa que plantea un debate sugerente sobre el origen del catarismo ${ }^{16}$. Más provocador es el libro del norteamericano Mark Gregory Pegg, que pone en duda la existencia misma de la herejía ${ }^{17}$. Y sobre el fenómeno herético y su persecución inquisitorial destacan el interesante estudio del hispanista británico Damian J. Smith y la síntesis del catalán Sergi Grau, que ofrece una perspectiva general de la herejía en los reinos hispánicos y dedica una parte de su libro a la posición adoptada por Pedro el Católico en relación con este problema ${ }^{18}$.

Conocemos mucho mejor la compleja realidad del espacio occitano gracias, entre otros trabajos, a las tesis doctorales de los discípulos de Pierre Bonnassie, en especial

${ }^{9}$ Cingolani, Historiografia, pp. 75-120.

${ }^{10}$ Cingolani, Jaume I, pp. 55-101.

${ }^{11}$ Cingolani (ed.), Gestes, 2008 (MHCA, 1); Libre dels reis, 2008 (MHCA, 2); Els annals (MHCA, 3); y Les "Gesta Comitum” (MHCA, 4). También Cingolani y Álvarez (ed.), Gestes, 2012.

${ }_{12}$ Meschini et al., Bibliografia, 2006.

${ }_{13}^{13}$ Martel, Les cathares, 2002; de este autor también El Jocs Florals, pp. 194-201; y Soula, Les cathares, 2005.

14 Alvira, La Cruzada, pp. 110-141.

${ }^{15}$ Aurell (dir.), Les cathares, 2005.

16 Jiménez, Les catharismes, 2008.

${ }^{17}$ Pegg, A Most Holy War, 2008. En la misma línea, Moore, The War, 2012.

${ }_{18}$ Smith, Crusade, 2010, pp. 31-39; y Grau, Catarismo, pp. 159-185 y 246-260. 
Laurent Macé para los condes de Tolosa y Hélène Débax para los vizcondes de la familia Trencavel ${ }^{19}$. En Cataluña, las relaciones occitano-catalanas en la Edad Media fueron el tema de exposiciones, conferencias y publicaciones en los años 2003-200420, destacando las aproximaciones de Almudena Blasco y Pere Benito a dos magnates cercanos a la jornada de Muret, el vizconde Gastó VI de Bearn y el conde Hug IV d'Empúries ${ }^{21}$. Más reciente y más importante es el buen estado de la cuestión sobre la política occitana de los condes de Barcelona y los reyes de la Corona de Aragón, estudiada en su momento por Josep M. Salrach y Mercè Aventin ${ }^{22}$, que ha elaborado Pere Benito como estudio preliminar al corpus documental que antes citamos ${ }^{23}$.

Las novedades son abundantes en la historiografía de la Cruzada Albigense. El primer gran coloquio internacional sobre este tema se celebró en el año 2002 en Carcassonne. Ya hemos citado parcialmente las actas, publicadas en 2004, en las que hay trabajos interesantes de numerosos especialistas de la historia medieval occitana ${ }^{24}$. El presidente del coloquio fue Michel Roquebert, renovador de los estudios sobre la batalla de Muret, cuya célebre "Epopeya cátara" se ha seguido publicando en diferentes formatos ${ }^{25}$. Una nueva aportación suya es una biografía del vencedor de la batalla, Simon de Montfort, publicada en $2005^{26}$. En Francia, la reciente conmemoración de los 800 años del inicio de la Cruzada Albigense (1209-2009) ha dado pie a la celebración de diferentes actos académicos y culturales. Algunos de ellos han visto la luz en publicaciones que analizan aspectos parciales (materiales, sociales, culturales, religiosos, militares, artísticos) de la realidad occitana del siglo XIII ${ }^{27}$. También se ha escrito en Italia una nueva síntesis divulgativa sobre esta guerra antiherética ${ }^{28}$.

El reinado de Pedro el Católico también ha recibido una cierta atención. El filólogo italiano Saverio Guida ha vuelto a poner de relieve las estrechas relaciones del monarca catalano-aragonés con la cultura trovadoresca ${ }^{29}$. Los cambios jurídicopolíticos de la monarquía y las relaciones del poder regio con otras fuerzas vivas son estudiadas por el medievalista Thomas N. Bisson, cuyas reflexiones se centran principalmente en Cataluña ${ }^{30}$. Los vínculos de Pedro el Católico con el papa Inocencio III, esenciales para comprender la posición de ambos en relación con la Cruzada

19 Macé, Les comtes, 2000 (reed. 2003); y Débax, La féodalité, 2003.

${ }^{20}$ Càtars $i$ trobadors, 2003 (para lo aquí nos interesa Débax, El fracàs, pp. 68-75); y Figueres (coord.), Col·loqui, 2004, en especial Mundó, Catalunya i Occitània, pp. 9-24; Riera, La desvinculació, pp. 57-80; Amado, À l'origine, pp. 81-108; y Rodríguez Bernal, L'alta noblesa, pp. 157-172.

21 Blasco, Gastó VI, pp. 141-156; Benito, La submissió, pp. 139-154.

22 Salrach, Relacions, pp. 12-22; y Aventin, Relacions, pp. 23-38.

23 Benito, L'expansió, pp. 13-150. Otra novedad, en el campo específico de la numismática, en Crusafont, Història, 2012.

24 Roquebert (dir.), La Croisade, 2004. Además de los citados, entre los autores figuran: M. Zerner, P. Jiménez, M. Meschini, C. Amado, E. Graham-Leigh, C. Keck, L. Macé, J.L. Biget, M. Mousnier, J.L. Abbé, D. Baudreu y C. Peytavie, M.E. Gardel y J.P. Cazes, D. Maso y N. Portet.

25 Roquebert, L'Épopée cathare, 1970, 1977, 1986, 1989 y 1998 (reed. 2001 y 2007-2008).

26 Roquebert, Simon de Montfort, pp. 276-315.

27 Bourin (dir.), En Languedoc, 2010; Au temps, 2009; y Au temps, 2010.

28 Meschini, L'eretica, 2010.

${ }^{29}$ Guida, Pietro il Cattolico, pp. 223-240. Más en general, también Espalader, El casal, pp. 106-123.

${ }^{30}$ Bisson, La crisis, pp. 420-428, 478-479, 488-489, 522-525, 560-577 y 620-621. 
Albigense y el origen de la batalla de 1213, se explican con detalle en los estudios de Damian J. Smith ${ }^{31}$, cuyas aportaciones pueden completarse con la tesis del especialista italiano Marco Meschini, publicada en el año $2007^{32}$. Y en el estudio ya citado, Pere Benito ofrece una correcta panorámica de su política ultrapirenaica y su proyecto de unificación occitana ${ }^{33}$. También ha habido acercamientos a la monarquía de Pedro el Católico desde un campo de investigación de cierta moda en los últimos tiempos, como es la movilidad de los entornos del poder-regio en particular- ${ }^{34}$. La aportación más novedosa en este ámbito es el estudio cartográfico del itinerario del rey Pedro realizado por Florent Laborie en una mémoire de maîtrise dirigida por Laurent Macé en $2005^{35}$. El precedente ineludible de la campaña de Muret es la batalla de Las Navas de Tolosa, cuyo centenario justifica el reciente estudio de la participación del rey de Aragón y sus hombres en la gran victoria cristiana ${ }^{36}$. Pero lo cierto es que Muret se explicaría mal sin tener en cuenta los acontecimientos políticos que ocurrieron en la ciudad de Tolosa a principios del año $1213 \mathrm{y}$, en especial, los llamados "Juramentos de Tolosa". El tema ha sido objeto de un estudio a tres manos que insiste en lo real del cambio político-jurídico derivado de la subordinación de los condes de Tolosa, Foix y Comminges, el vizconde de Bearn y los cónsules de las ciudades de Toulouse y Montauban a la autoridad regia de Pedro el Católico, y el nacimiento de lo que hemos denominado "Gran Corona de Aragón" ${ }^{37}$.

Donde realmente pueden encontrarse aportaciones susceptibles de modificar nuestros conocimientos de lo sucedido en la batalla de Muret es en el ámbito de la historia de la guerra. Comencemos por un campo de trabajo específico y novedoso como es el de las prácticas guerreras, en especial de los caballeros. El excelente estudio del especialista británico Matthew Strickland, dedicado a la conducción y la percepción de la guerra en el mundo anglonormando, ofrece un sinfín de sugerentes ideas que deberían haberse aplicado antes al caso de Muret. Un buen ejemplo es el episodio de los llamados "desafíos de Muret", ocurrido en febrero de 1213 en la curia regia reunida en Perpiñán o Collioure ${ }^{38}$. De regreso de Tolosa y tras haberse hecho prestar juramento por los nobles y las ciudades occitanas, el rey de Aragón "desafió" a Simon de Montfort (diffidat rex comitem, dice la Hystoria Albigensis de Pierre des Vaux-de-Cernay, que es quien nos informa de lo ocurrido) ${ }^{39}$. La diffidatio, más que un "desafío" en sentido estricto, era la "ruptura de la fe", esto es, la renuncia formal al homenaje feudal, lo que se entendía en efecto como una declaración formal de hostilidades, como "una forma ritualizada de señalar de forma inequívoca la transición de un estado de paz a un estado de guerra" ${ }^{40}$. Este anuncio servía al mismo tiempo para

\footnotetext{
${ }^{31}$ Smith, Peter II, pp. 1.049-1.064; Aragon, pp. 157-170; e Innocent III, pp. 111-141.

${ }_{32}$ Meschini, Innocenzo III, pp. 636-670. De este autor, también "Pro negotio", pp. 159-185.

${ }^{33}$ Benito, L'expansió, esp. pp. 100-130.

${ }^{34}$ Macé, "Viator rex", 2009; y Alvira, Itinerarios, 2013.

${ }^{35}$ Laborie, Les itinéraires, 2005.

${ }^{36}$ Alvira, El rey de Aragón, en prensa; y Alvira, Las Navas, esp. 415-419.

${ }^{37}$ Alvira; Macé; Smith, Le temps, pp. 1-22.

${ }^{38}$ Roquebert, L’Épopée, II (1977), pp. 131-132; y sobre todo Alvira, El Jueves, pp. 176-180; y Muret,

${ }^{39}$ Pierre des Vaux-de-Cernay, $\S \S 413-416$.

${ }^{40}$ Strickland, War, pp. 40-42 (trad. nuestra).
} pp. 68-71. 
avisar al vasallo o señor desligado de un inminente ataque, si bien no parece que los reyes -según Strickland- "sintieran la obligación de desafiar a sus antiguos vasallos antes de atacarlos" "11, a diferencia de lo que sí hizo Pedro el Católico con Simon de Montfort antes de Muret. La respuesta del caudillo cruzado fue "desafiar" a su vez al monarca, rompiendo el vasallaje que le debía en tanto que vizconde de Besièrs y Carcassona. El caballero francés Lambert de Thury formalizó la ruptura por medio de una carta de Montfort que fue leída por un obispo ${ }^{42}$. El rey, airado, ordenó prenderle y algunos de sus barones sugirieron que se le ejecutara si Montfort no comparecía ${ }^{43}$. Al día siguiente, Lambert se presentó de nuevo ante la curia regia y retó a cualquiera que dudara de la fidelidad de su señor. Esta segunda forma de desafío -duellum escribe Vaux-de-Cernay ${ }^{44}$ - era más común en el mundo caballeresco. Se entendía como una afirmación publica de legitimidad y un gesto intimidatorio de agresividad, cercano incluso a la bravuconada. En este sentido, y como ha comprobado Strickland, estos desafíos podían tener un propósito preventivo: evitar una batalla o, al menos, aplazarla y ganar tiempo de cara a una posible negociación, con el consiguiente acrecentamiento de la moral de los partidarios del retador ${ }^{45}$. En nuestro caso, el desafío de Lambert de Thury parece una reacción caballeresca a la difícil situación personal del cruzado francés, pero hay un hecho apreciado por Strickland que resulta interesante contemplando la escena en vísperas de la batalla de Muret: los desafíos solían ser una iniciativa del bando que se encontraba en situación de desventaja militar y solían ser rechazados por el bando más poderoso. En nuestro caso, ninguno de los barones del rey de Aragón aceptó el desafío planteado por el caballero de Simon de Montfort, lo que vendría a confirmar dos cosas: una, la posición de fuerza de la que gozaba Pedro el Católico antes de intervenir militarmente en territorio occitano; y dos, la condición de último recurso que, para los cruzados, significó hacer frente al ejército del monarca hispano-occitano en un choque frontal en campo abierto.

Volviendo a la historiografía, y si de la batalla de Muret se trata, las aportaciones de los últimos años no son escasas, aunque sí muy desiguales y pocas veces novedosas. La batalla ha sido dada a conocer en síntesis dirigidas al gran público ${ }^{46}$, ensayos reivindicativos ${ }^{47}$, publicaciones oficiales de la propia ciudad de Muret $^{48}$ y varios artículos escritos en revistas históricas de carácter divulgativo por autores ajenos al mundo académico ${ }^{49}$. Desde planteamientos más profundos, en el coloquio sobre la Cruzada Albigense del año 2002, el gran medievalista Philippe Contamine analizó la dimensión francesa de Muret -en comparación con la batalla de Bouvines-, la inter-

\footnotetext{
${ }^{41}$ Ibidem, pp. 40-41 (trad. nuestra).

${ }^{42}$ García Frontín, obispo de Tarazona, o Guillem de Tavertet, obispo de Vic (Alvira, Pedro el Católico, vol. III, $\left.\mathrm{n}^{\circ} 1.470-1.471\right)$.

${ }^{43}$ Los participantes laicos en esta curia en ibidem, $\mathrm{n}^{\circ}$. 1.466, 1.468-1.471 (febrero), 1.475, 1.476, 1.479, 1.481 y 1.482 (marzo).

${ }^{44}$ Pierre des Vaux-de-Cernay, § 416. Cembellum en el ámbito anglonormando, Strickland, War, pp. 42-43.

${ }^{45}$ Strickland, War, pp. 42-44; y Provoking, pp. 317-343, esp. 323-325 y 342.

${ }^{46}$ Meschini, L'eretica, pp. 207-239, esp. 219-239.

47 Escura, Els mites, pp. 27-52.

${ }^{48}$ Galey y Bonnet, 12 septembre 1213, 2005.

${ }^{49}$ Gasc, La bataille, pp. 82-90; Sella et al., 1213, pp. 24-31; Dalmau, El triunfo, pp. 80-91; Vélez, Muret, pp. 94-95; y Odalric, La batalla, pp. 58-65.
} 
pretación que de ella dieron las fuentes de la monarquía Capeto y sus consecuencias para la formación de la Francia medieval ${ }^{50}$. En las mismas actas se estudiaron también los aspectos culturales, ideológicos y mentales que estuvieron presentes en la génesis de la batalla ${ }^{51}$. Y más recientemente, se han intentado comprender el recuerdo de Muret en la historiografía contemporánea y el hecho de la batalla en su contexto "internacional" específico, que fue el de los grandes conflictos que enfrentaron a cristianos y almohades en la Península Ibérica, a franceses, angevinos e imperiales en el norte de Francia y a cruzados y occitanos en el sur de Francia, todos ellos bajo la mirada atenta (y mucho más que la mirada) del papa Inocencio III ${ }^{52}$.

El desarrollo estrictamente militar de la batalla también se ha estudiado, si bien casi siempre en el seno de estudios de carácter más general. Permítasenos comenzar este apartado comentando algunos trabajos pioneros que no han sido publicados y que, por lo tanto, siguen siendo difíciles de consultar, sobre todo por los especialistas no anglosajones. El más antiguo es la tesis (M.A. dissertation) del medievalista norteamericano John Hine Mundy, más conocido por sus contribuciones a la historia de la vida social y económica de Toulouse en los siglos XII-XIII. Se leyó en la Universidad de Columbia en junio de $1941 \mathrm{y}$, como indica el título, es un estudio militar de la Cruzada Albigense ${ }^{53}$. Mundy partía de una apreciación correcta: en el seno de una historiografía militar aferrada desde el siglo XIX a la batalla campal como forma máxima y casi única de enfrentamiento bélico, la batalla de Muret había monopolizado la atención de los historiadores de la guerra medieval, por lo que era necesario insistir en otros aspectos (organizativos sobre todo) de la Cruzada Albigense ${ }^{54}$. Para ello, este autor manejó la bibliografía académica disponible (sobre todo francesa) y se valió de las aportaciones de historiadores militares alemanes (Wilhelm Erben, Eugen von Fraunholz) y británicos (Charles Oman, Hoffman Nickerson). Con todo, su principal mérito es haber exprimido las fuentes documentales y cronísticas editadas, incluyendo tres hispánicas ${ }^{55}$. Los primeros tres capítulos de su trabajo son los más innovadores. En ellos se estudian las formas de reclutamiento y servicio militar, la financiación (sobre todo eclesiástica), la logística y los ejércitos (equipamiento, tácticas, composición, fortificaciones). La segunda mitad de la tesis es una historia militar de la Cruzada dividida en otros tres capítulos. La batalla de Muret se sitúa en el segundo, que Mundy tituló "Spanish Intervention and the Victory of the Crusade" (section 5, pp. 122-160). A la jornada de 1213 le dedicó 21 páginas (10\% del total), lo que no es poco teniendo en cuenta que su estudio alcanza hasta 1229 .

Su explicación del origen del choque está muy condicionada por la perspectiva francesa de los acontecimientos, por lo que no habla de las iniciativas diplomáticas de Pedro el Católico en Roma, ni de los "Juramentos de Tolosa" ni de sus consecuen-

${ }^{50}$ Contamine, Le Jeudi, pp. 109-123.

${ }^{51}$ Alvira, Le Jeudi, pp. 197-207.

${ }^{52}$ Alvira, Después, pp. 85-111.

${ }_{53}$ Mundy, The Albigensian Crusade, 1941 (dir. Austin P. Evans).

${ }^{54}$ Sobre el papel central de la batalla entre los historiadores contemporáneos de la guerra medieval, García Fitz, Las Navas, pp. 15-40; y La batalla, pp. 93-108.

${ }^{55}$ Gesta Comitum Barchinonensium, Jaime I y Rodrigo Jiménez de Rada. No utilizó ningún autor español contemporáneo. 
cias geopolíticas ${ }^{56}$. Mundy hizo una relectura de la batalla a partir de las fuentes y de los estudios de Delpech, Molinier, Köhler, Oman, Dieulafoy, Anglade y Nickerson ${ }^{57}$. Este último había escrito ampliamente sobre Muret en una historia político-militar de la Inquisición (1923; reed. 1932), en una historia de la guerra medieval (1925) y, sobre todo, en un interesante artículo de 1931 en el que rebatía la interpretación del choque dada en 1898 y 1924 por el célebre historiador de la guerra británico Charles Oman $^{58}$. Como señaló el propio Mundy, las aportaciones de Nickerson-que creyó brillantes aunque no las compartiera- demostraban que lo ocurrido en el campo de batalla de Muret estaba lejos de ser un debate cerrado ("far from dead"), una afirmación que puede seguir manteniéndose siete décadas más tarde ${ }^{59}$.

Mundy comenzó por afirmar que las tropas de Pedro el Católico atravesaron los Pirineos por el Alto Aragón y no por la Cerdaña, como había sostenido Nickerson ${ }^{60}$. No quiso entrar en el espinoso tema del volumen de los ejércitos ${ }^{61}$, pero sí en el de la posición del campamento hispano-occitano, unos de los problemas centrales en la explicación de la batalla. El único autor del siglo XIII que situó el campamento es el clérigo tolosano Guilhem de Puèglaurenç: castra essent ab occidente ${ }^{62}$. A partir de este dato, Henri Delpech, Marcel Dieulafoy y la mayoría de los estudiosos han sostenido que el campamento se extendía al oeste-noroeste de Muret, en la orilla izquierda del río Saudrune y entre la elevación de Perramon (al sur) y el camino de Seysses y Toulouse (al norte) ${ }^{63}$. Otros autores, comenzando por Gustav Köhler y Charles Oman, negaron el testimonio de Puèglaurenç (afirmando que pudo equivocarse al escribir occidente cuando en realidad quería decir oriente) y sostuvieron con argumentos militares -éstos sí más razonables- que el campamento se encontraba al norte-nordeste de Muret, entre el camino de Tolosa y la orilla izquierda del Garona ${ }^{64}$. John H. Mundy se reconocía consciente de estar negando las fuentes, pero apostó por la segunda hipótesis atendiendo a varias razones: la ruta natural de aprovisionamiento (y retirada) del ejército del rey de Aragón era la que conducía hacia el norte, hacia Toulouse; situar el campamento cerca de Perramon habría facilitado una salida exitosa de los cruzados contra las tropas tolosanas, en especial contra sus máquinas de asedio; hay demasiada distancia entre el campamento tolosano de Perramon y las

56 Mundy, The Albigensian Crusade, pp. 132-135.

${ }^{57}$ Ibidem, pp. 136-153. Referencias en la bibliografía y, con más detalle, en el estudio citado en la nota 1.

58 Oman, A History (1924), I, pp. 453-467; Nickerson, The Inquisition, 1923; reed. 1932, pp. 151-169; Warfare, reed. 2003, pp. 146-156; y Oman's Muret, pp. 550-572.

59 Mundy, The Albigensian Crusade, pp. 1-2. Son interesantes los cálculos que hizo Nickerson de las distancias cubiertas por las columnas de jinetes cruzados en su salida de Muret, de sus velocidades de avance y de los tiempos que emplearon hasta chocar con las tropas enemigas (The Inquisition, 1932, pp. 163-164).

${ }^{60}$ Ibidem, p. 136; Nickerson, The Inquisition, pp. 151-153.

${ }^{61}$ Mundy, The Albigensian Crusade, pp. 138-139.

${ }^{62}$ Guilhem de Puèglaurenç, cap. 20, p. 88.

63 Delpech, La bataille, pp. 1-7 (La tactique, I, pp. 188-191); y Dieulafoy, La bataille, pp. 106-108. Hipótesis sostenida por Dévoluy (1907), Anglade (1913), Nickerson (1923, 1925 y 1931), Belperron (1942), Lot (1946), Ventura (1960), Roquebert (1977), Sumption (1978), Escura (1998 y 2003), Noah (1999), Alvira (2002 y parcialmente 2008), Meschini (2005 y 2010), Marvin (2008) y Nicolle (2011).

${ }^{64}$ Köhler, Die Entwickelung, I, pp. 83-116, esp. 97; y Oman, A History, I, p. 457. Hipótesis seguida por Dalmau (1960), Hernàndez (2002), Bennett et al. (2005) y, parcialmente, Alvira (2008). 
barcazas del Garona hacia las que huyeron en la fase final de la batalla; no es posible que los tolosanos no vieran la derrota del rey de Aragón desde la elevación de Perramon y sí estando acampados al norte; y si el conde de Tolosa situó a su joven hijo Raimondet de Tolosa en la elevación de Perramon fue justamente para alejarlo de su campamento, objetivo potencial de Simon de Montfort, lo que demuestra que no estaban acampados allí, sino al norte ${ }^{65}$.

Mundy fue original a la hora de sostener que Pedro el Católico probablemente no quería librar la batalla ese jueves 12 de septiembre, pues esperaba los refuerzos catalanes que llegaban con su primo Nunó Sanç y Guillem Ramon de Montcada, aunque esta idea contradice abiertamente el testimonio de Jaime $\mathrm{I}^{66}$. En su opinión, el rey de Aragón formó su ejército sobre el campo con el objetivo de sostener el ataque inicial de las tropas hispano-occitanas contra la Puerta de Tolosa ${ }^{67}$, pero la batalla fue precipitada por la salida de los cruzados de Muret. Para explicar el enfrentamiento, Mundy dejó de lado la interpretación de Marcel Dieulafoy y retomó la de Henri Delpech en la versión de Gustav Köhler y Charles Oman: los cruzados salieron por la Puerta de Salas para dirigirse hacia el oeste hasta vadear el río Loja (Louge) y entrar en el campo de batalla ${ }^{68}$. Su relato de los hechos resulta convincente y se parece mucho a una de las hipótesis que planteamos recientemente ${ }^{69}$. En cuanto a valoración de las consecuencias históricas de la batalla, Mundy no llegó tan lejos como Nickerson, pero sí afirmó que "Muret was decisive", porque marcó el inicio de una nueva fase de la Cruzada Albigense y porque "the King of Aragon has been killed, and this death marked the practical end of Spanish intervention in the conflict"

Un segundo trabajo inédito que vale la pena recordar se leyó en Glasgow en noviembre de 1999. Se trata de la tesis de Rachel Louise Noah, que dirigió Matthew Strickland bajo el título de Military Aspects of the Albigensian Crusade ${ }^{71}$. Se trata de un trabajo enmarcado en el resurgimiento de la nueva Historia Militar Medieval, cuyas aportaciones la autora quiso trasladar al caso de la guerra albigense. El estudio de Noah retoma el interés por los aspectos organizativos de la Cruzada Albigense (reclutamiento y composición de los ejércitos, uso de tropas mercenarias y a sueldo), las fortificaciones y la guerra de asedio. El quinto y último capítulo se dedica a las operaciones de desgaste, contempladas sólo superficialmente, y a las batallas campales. El

${ }^{65}$ Mundy, The Albigensian Crusade, pp. 140-144.

${ }^{66}$ Jaime I, cap. 9, p. 13.

${ }^{67}$ Ibidem, p. 145.

${ }^{68}$ Dieulafoy afirmó que los cruzados salieron por la Puerta de Salas, giraron a la izquierda para bordear la orilla del Garona y cruzaron el Loja por el Puente de Sant Sernin, al pie del castillo de Muret, en el extremo oriental de la villa (La bataille, pp. 121-125). Esta hipótesis fue compartida por Dévoluy (1907), Anglade (1913), Nickerson (1923, 1925 y 1931), Belperron (1942), Lot (1946), Ventura (1960), Roquebert (1977), Sumption (1978), Escura (1998 y 2003), Noah (1999), Alvira (2002 y parcialmente 2008), Meschini (2005 y 2010), Marvin (2008) y Nicolle (2011).

${ }^{69}$ Mundy, The Albigensian Crusade, pp. 145-152; y Alvira, Muret, pp. 358-359.

${ }^{70}$ Mundy, The Albigensian Crusade, pp. 153-154. Para Nickerson, "a different result at Muret might well have produced a great Provençal-speaking state on both sides of the Pyrenees, hindering if not preventing the national formation of both France and Spain" (Oman's Muret, pp. 551-552).

${ }^{71}$ Noah, Military Aspects, 1999. 
mérito de Noah reside en haber hecho una sistemática comparativa entre la realidad militar del norte de Francia (la monarquía Capeto) y de los territorios occitanos.

A la hora de tratar de Muret, y como en otros apartados de su estudio, Noah hizo un estudio paralelo, aunque sólo parcialmente comparado, entre una batalla del sur de Francia (Muret) y una del norte de Francia (Bouvines) ${ }^{72}$. Su análisis del choque de 1213 comienza mostrándose de acuerdo con el más tarde llamado "paradigma Gillingham", que insiste en que la batalla campal no era una estrategia buscada por los caudillos medievales ${ }^{73}$. Esta idea le lleva a negar con razón que Simon de Montfort siguiera una estrategia basada en librar choques campales ${ }^{74}$. Noah reivindica asimismo las funciones logísticas de la infantería occitana y compara atinadamente Muret con la batalla de Saint-Martin-la-Lande o Castelnaudary (1211). En el análisis de la jornada de 1213, se declara consciente de los problemas que ofrecen tanto las fuentes medievales como las especulaciones de los especialistas contemporáneos, principalmente británicos y norteamericanos (no conoce ningún historiador español). Entre estos trabajos, maneja muchos de los "clásicos" (Delpech, Molinier, Dieulafoy, Oman, Delbrück, Belperron, Lot), pero desconoce los pioneros de Hoffman Nickerson y John $\mathrm{H}$. Mundy, algo que sorprende en una investigación procedente del ámbito anglosajón. Aprovecha bien, en cambio, el estudio renovador de Michel Roquebert (1977) y las aportaciones de Jonathan Sumption (1978) ${ }^{75}$.

El libro de este último autor, juez, escritor e historiador británico, es una síntesis de la Cruzada Albigense y los orígenes de la Inquisición de carácter divulgativo, aunque bien construida y bastante bien documentada ${ }^{76}$. El capítulo diez se dedica a la batalla de Muret, que reconstruyó a partir de las fuentes y los estudios de Delpech, Dieulafoy, Oman y Belperron, si bien cita también a Lot y al historiador catalán Jordi Ventura, el primer autor español en retomar de forma monográfica el estudio de la batalla de Muret y sus circunstancias ${ }^{77}$. No utilizó, sin embargo, los trabajos de Nickerson ni de Mundy, curiosamente (o no) los mismos que ignoró luego Rachel L. Noah. El planteamiento de Sumption sobre la posición política del rey de Aragón antes de Muret fue más completo que el de los autores anglosajones anteriores, pues señaló los vínculos feudales que le unían a los nobles occitanos y los intereses ultrapirenaicos que le movían ${ }^{78}$. En cuanto a la batalla, ofreció cifras moderadas para el ejército catalano-aragonés ( 800 jinetes, más 200 de camino) y bajas para la caballería occitana (600 jinetes), sosteniendo que la superioridad hispano-occitana en infantería resultó irrelevante por la incompetencia militar de la milicia tolosana. Al margen de lo discutible de esta afirmación genérica, su relato de la batalla presenta algunas fallas notables. Situó el campamento del rey de Aragón al noroeste, al otro lado del río

\footnotetext{
${ }^{72}$ Ibidem, pp. 119-129, esp. 123-129 (Muret), y 129-131 (Bouvines).

${ }^{73}$ El debate de los especialistas en torno a este "paradigma" puede verse en Monteiro, Estratégia, pp. 149-155.

${ }^{74}$ Idea sostenida por Verbruggen, The Art of Warfare, p. 252; y negada también por Alvira, El Jueves, p. 226.

${ }^{75}$ Referencias en notas previas y en la bibliografía.

${ }^{76}$ Sumption, Albigensian Crusade, 1978 (carece de notas).

${ }_{77}$ Ibidem, pp. 156-170, 254-255 (n. 22) y 258-260 (bibliografía).

${ }^{78}$ Ibidem, pp. 156-163.
} 
Saudrune, ubicando luego el campamento tolosano al oeste de las murallas de Muret, entre las orillas del Garona y el Loja, y las barcazas procedentes de Tolosa al sur de la villa, lo que hace incomprensible el desarrollo de la batalla ${ }^{79}$. Negó también el testimonio de la Cansó de la Crozada -cuando afirma que el rey Pedro ordenó detener el ataque a las murallas de Muret ante la llegada del ejército cruzado ${ }^{80}$ - al asegurar que los occitanos se retiraron movidos por el pánico, afirmando que debieron haber aprovechado la ocasión para atacar a las fuerzas de Montfort cuando entraban en la villa. Sumption interpretó el cambio de armas de Pedro el Católico antes del choque como un gesto de vanidad, es decir, desde el mismo tópico que ya sostuviera en su día Oman (quien consideró al rey de Aragón un "knight errant"81). En el desarrollo de la batalla, Sumption siguió la versión de Dieulafoy y la valoración de Oman: Muret fue "a rout, not a battle". El choque duró veinte minutos y fueron los errores en el mando los que provocaron la derrota de Pedro el Católico. Su percepción, en este punto, no es errónea, especialmente cuando afirma que el rey de Aragón tenía las ventajas del número y el terreno, pero no aprovechó ninguna ${ }^{82}$.

Las ideas expuestas en el libro de Sumption fueron comentadas y no siempre desmentidas en la tesis de Rachel L. Noah, quien sí criticó los errores de la versión de Charles Oman, la más aceptada entre los historiadores anglófonos ${ }^{83}$. Algunas de sus afirmaciones, sin embargo, son discutibles, como cuando sugiere que Simon de Montfort no acudió a Muret con la idea de enfrentarse al rey de Aragón, sino de conservar la plaza y esperar refuerzos franceses procedentes del norte ${ }^{84}$. Tampoco se entiende bien o es errónea su interpretación de la salida de los cruzados de Muret en distintas direcciones ${ }^{85}$. En realidad, esta autora no acaba de decantarse por ninguna de las versiones y no entra a discutir los problemas esenciales de la batalla: el lugar del choque; la posición del campamento hispano-occitano (acepta que estaba en la orilla izquierda del Garona, al norte-nordeste de Muret); el movimiento de flanqueo del tercer haz liderado por Simon de Montfort; el papel de los condes de Tolosa y Comminges en la batalla. Su valoración de la derrota de Pedro el Católico debe mucho a Sumption, salvo en dos aportaciones interesantes: la justificación tanto de la posición del monarca en el haz central como de su muerte, debida a los riesgos que corrían los caudillos medievales en combate; y la tradicional explicación de la pasividad de los condes occitanos en la batalla como fruto de la impresión que, conscientemente, quisieron dar los autores de las fuentes a posteriori (en especial, el anónimo tolosano autor de la Cansó).

\footnotetext{
${ }^{79}$ Ibidem, 168 (mapa).

${ }^{80}$ Cansó, estrofa 137. La idea del pánico de los occitanos ya en Dieulafoy, La bataille, p. 112.

${ }^{81}$ Oman, A History, p. 453.

${ }^{82}$ Sumption, Albigensian Crusade, pp. 165-170, esp. 168.

${ }^{83}$ Noah, Military Aspects, pp. 125-127.

${ }^{84}$ Ibidem, p. 126; opinión contraria en Alvira, El Jueves, pp. 211-226; y Muret, pp. 101-120.

85 "One part of the crusader army attacked at the Port au [sic] Sales, a second at the East gate of the town, the third part removed themselves to the Fanjeaux road, crossed the Longe [sic] and arrived within sight of the enemy", ibidem, p. 127.
} 
Estos estudios militares de la Cruzada Albigense en lengua inglesa han tenido recientemente su colofón en The Occitan War. A Military and Political History of the Albigensian Crusade, 1209-1218, un libro publicado en el año 2008 por el norteamericano Lawrence W. Marvin ${ }^{86}$. Constituye otra aplicación de los métodos de trabajo y las conclusiones de los modernos historiadores anglosajones de la guerra medieval a la Cruzada Albigense. En Marvin sí encontramos un buen uso de los estudios previos de Mundy y Noah, así como un meritorio aprovechamiento (para un anglófono) de la bibliografia escrita en francés e incluso en español (aunque en este último caso con dificultades). El principal problema de este trabajo es una cronología que se interrumpe en 1218, fecha de la muerte de Simon de Montfort, por lo que se dejan fuera del estudio los últimos diez años del conflicto albigense.

Marvin dedica casi todo el capítulo seis de su libro a la jornada de 1213. Primero describe con rigor su génesis política ${ }^{87}$. Luego hace una interesante valoración de la batalla, a la que cree comparable a Hastings, Las Navas de Tolosa, Bouvines y Courtrai ${ }^{88}$. El autor también acierta al vincular los choques de Muret y Saint-Martin-la-Lande o Castelnaudary (1211), pues ambos presentan elementos comunes. Su narración de los hechos bebe en las fuentes principales, la bibliografía tradicional y los estudios más recientes ${ }^{89}$. Como antes hicieran Roquebert y Alvira (2002), Marvin opta por dar más verosimilitud a las versiones de Pierre des Vaux-de-Cernay y Guilhem de Puèglaurenç que a la fragmentada del continuador tolosano de la Cansó, por lo que apenas difiere de las interpretaciones de estos autores ${ }^{90}$. Es más original, en cambio, cuando sugiere lo que debería haber hecho el rey de Aragón para vencer la batalla: ordenar que sus tropas atravesaran el Garona para rodear Muret por todas partes y bien lanzar un asalto masivo y definitivo, bien bloquear la plaza hasta que cayera por hambre ${ }^{91}$. Igualmente interesante es su valoración del comportamiento de Simon de Montfort, que considera "inexplicable" desde un punto de vista militar. En lugar de salir de Muret a campo abierto para enfrentarse a un ejército muy superior en número, sin posibilidades de retirada, sin reservas y con pocos suministros, Marvin sugiere que debería haber esperado a la defensiva, aprovechando las mayores ventajas que los defensores de una plaza tenían siempre respecto de los atacantes y esperando a que éstos sufrieran problemas internos de abastecimiento y/o disputas internas. Marvin sostiene, por lo tanto, que la decisión de Simon de Montfort fue muy arriesgada. En su opinión, el caudillo cruzado se lo jugó todo a una carta que al final le salió bien, pero que también pudo acabar en un desastre. Muret fue una bata-

86 Marvin, The Occitan War, 2008.

${ }^{87}$ Ibidem, pp. 158-195, esp. 175-195.

88 Ibidem, pp. 175-176.

89 Delpech (1878), Dieulafoy (1899-1901), Anglade (1913), Delbrück (1900-1920), Oman (1898 y 1924), Nickerson (1923, 1925 y 1931), Lot (1946), Kovarik (1963), Evans (1962), Strayer (1971), Roquebert (1977), Sumption (1978) y Alvira (2002).

${ }^{90}$ Ibidem, p. 158 (campamento situado al oeste-noroeste de Muret; salida de los cruzados por la Puerta de Salas y el Puente de Sant Sernin; maniobra de Simon de Montfort por la izquierda contra el flanco derecho hispano-occitano; distinción entre la batalla campal de los caballeros y la masacre posterior de los peones).

${ }^{91}$ Ibidem, p. 182. 
1la campal, porque tanto Pedro como Simon -dice Marvin- "were willing to let God show his favor to one of them"92.

Este autor vuelve a poner sobre la mesa algunos de los problemas interpretativos del choque: las cifras de combatientes y bajas; las incompatibilidades de las fuentes a la hora de explicar la salida de los cruzados; o cómo murió el rey de Aragón, cuestión para la que prescinde del importante testimonio de la crónica de Baudouin d'Avesnes ${ }^{33}$. Su retrato de Pedro el Católico resulta moderado y razonable, pues le reconoce virtudes militares, explica el buen sentido táctico que tenía su ubicación en el haz central y confirma que fue su muerte la que hizo de Muret un triunfo indiscutible para Simon de Montfort. Para Marvin, la derrota catalano-aragonesa tiene su mejor explicación en la crónica de Jaime I: una peligrosa combinación de errores militares -división de fuerzas, ausencia de mando regio sobre la milicia tolosana, mal orden de combate-, exceso de confianza en una victoria que el rey celebró antes de tiempo, condicionando su buen juicio en el combate, y una excelente actuación del ejército cruzado. La batalla de 1213, dice este autor, fue "una de las victorias tácticas más decisivas" de la historia europea plenomedieval, "comparable to Hastings tactically and a greater battlefield achievement than Bouvines" "94. Aún así, insiste en censurar el papel de Montfort en la victoria. En su opinión, el líder de la Cruzada demostró en Muret ser "a general of considerable skill", pero "not necessarily a tactical genius", tal como asegurara en su momento Johan Verbruggen ${ }^{95}$.

La valoración que hace Marvin de las consecuencias a medio y largo plazo de la derrota hispano-occitana presenta luces y sombras. Acierta al sostener que Muret fue un triunfo provisional para Simon de Montfort y que acabó con la posibilidad de una nueva intervención militar de la Corona de Aragón en el espacio occitano a corto plazo. Mucho más discutible es su afirmación de que la victoria de los cruzados significó un retorno a la situación anterior a la intervención del rey de Aragón ${ }^{96}$. No fue así, creemos, desde el momento en que el descabezamiento de la monarquía catalanoaragonesa y la paralización de su política ultrapirenaica durante más de quince años acabó con el único aliado política y militarmente activo de los occitanos enfrentados a la Cruzada Albigense y al rey de Francia, condenándoles a una derrota prácticamente segura en el medio y largo plazo ${ }^{97}$.

Otros especialistas han escrito sobre la batalla de Muret en obras de temáticas militar, pero con un espíritu eminentemente divulgativo y sin ánimo de dar respuesta a las incógnitas de la batalla. Es el caso de las descripciones mínimas de Jim Bradbury (2006), John France (2009) y Lawrence W. Marvin (2010)98, el mapa de David Nicolle (2011) y las versiones sintéticas de Martín Alvira (2005), Marco Meschini (2005) y el portugués João Gouveia Monteiro (2011), quienes reproducen la interpretación

\footnotetext{
92 Ibidem, p. 183; siguiendo la idea apuntada por Alvira, El Jueves, pp. 202-209.

93 Chronique, pp. 52-54.

94 Marvin, The Occitan War, pp. 183-193 (cita p. 192).

95 Ibidem, pp. 193-194; Verbruggen, The Art of Warfare, pp. 251-252

96 Marvin, The Occitan War, pp. 194-195.

97 Alvira, El Jueves, pp. 530-534; y Muret, pp. 236-238.

98 Bradbury, Medieval Warfare, p. 204; France, A Changing, pp. 160 y 170; y Marvin, Muret, pp. 36-37.
} 
de la batalla dada por Michel Roquebert (1977) y mantenida por Alvira (2002) ${ }^{99}$. En el ámbito anglófono, un trabajo colectivo de divulgación dirigido por el especialista Matthew Bennett en 2005 ha vuelto, en cambio, a la interpretación de Charles Oman, que adolece de errores graves ${ }^{100}$. Lo más interesante de este libro es la descripción de las maniobras de las columnas de caballería de Simon de Montfort y los cálculos del espacio que habrían ocupado en el momento de salir de Muret ${ }^{101}$.

En España, y siguiendo en el ámbito de la guerra medieval, el escaso interés de los historiadores de la Corona de Aragón plenomedieval por este campo de estudio explica que las novedades sobre la batalla de Muret hayan tenido un carácter divulgativo y/o provengan de autores que no son medievalistas, ni historiadores profesionales con un anclaje académico. Es cierto que esta circunstancia no tiene por qué ser incompatible con un estudio riguroso del pasado, como demostraron en su día los historiadores franceses no universitarios del catarismo y la Cruzada Albigense ${ }^{102}$, pero no parece que éste sea el caso de la batalla de Muret. Un ejemplo de ello es el libro sobre batallas decisivas de la Historia de España de Juan Carlos Losada (2004). El capítulo dedicado a la jornada de 1213 es breve, sin notas, inspirado -según el autor- en $L a$ hoguera de Montsegur de Zoé Oldenbourg (no cita otros trabajos) y repite lugares comunes y errores históricos ${ }^{103}$.

Mejor nivel presenta el segundo volumen de la Història Militar de Catalunya, que en 2002 publicó el entonces Profesor Titular de Didáctica de las Ciencias Sociales F. Xavier Hernàndez Cardona ${ }^{104}$. La iniciativa resulta interesante y novedosa, sobre todo teniendo en cuenta el tradicional desapego de la moderna historiografía catalana por la historia militar plenomedieval. La obra, de finalidad didáctica y dirigida a un público amplio, ofrece un muy buen aparato gráfico, especialmente en lo que se refiere a planos de batallas y a dibujos (b/n) de combatientes y armamento de la época, obra estos últimos del dibujante Francesc Riart ${ }^{105}$. La colaboración de estos dos

99 Nicolle; Hook, European, p. 58 (plano de la batalla tomado de Meschini); Alvira, "Le jugement", pp. 73-82; Meschini, Battaglie, pp. 163-193; y Monteiro, A arte militar, pp. 27-30. Roquebert, L'Épopée, II (1977), pp. 187-236.

${ }^{100}$ Bennett, Técnicas bélicas, pp. 146-147 (plano de la batalla), 148-150 y 154. El error principal de Oman fue sostener que el ejército formado por Pedro el Católico era una combinación de jinetes y peones, cuando las fuentes sugieren que la infantería no tuvo ningún papel en la batalla.

101 Ibidem, p. 150.

102 Pensamos, por ejemplo, en los citados Jean Duvernoy y Michel Roquebert.

${ }^{103}$ Losada, Batallas, pp. 77-88: equivoca la fecha de la batalla (13 de septiembre); ofrece un retrato simple y caballeresco de Pedro el Católico; comenta el carácter fanático de los cruzados; afirma que Santo Domingo de Guzmán acompañaba a Simon de Montfort; habla de 40.000 peones occitanos y de casi 7.000 cruzados; asegura que el rey cambió su armadura con un caballero para acercarse mejor al enemigo; cree que el haz de Montfort cargó contra el haz del rey; y en los cuatro planos de la batalla se entremezclan confusamente las distintas versiones del choque.

104 Hernàndez, Història, 2002.

105 Este autor ya había ilustrado de forma notable una publicación divulgativa sobre el mundo occitano del siglo XIII, el catarismo y la Cruzada Albigense (Escura; Riart; Garcia, Càtars, pp. 58-77, esp. 76-77). Tres de estos dibujos se incorporaron a la obra de Hernàndez para acompañar el relato de la batalla de Muret, siendo una lástima que otros -en especial una escena a doble página de la batalla (pp. 76-77)- no pudieran hacerlo. Riart dibujó también dos planos tridimensionales de la batalla con la interpretación de Dieulafoy heredada por Ventura y rebatida por Roquebert ya en 1977. El texto de esta publicación se inspira en la obra de Jordi Ventura, pero carece de rigor histórico. 
autores se ha plasmado en una reciente publicación sobre los ejércitos de Jaime I que sobresale por sus cuidadas ilustraciones ${ }^{106}$.

Hernàndez describe la batalla de Muret partiendo de las fuentes, los estudios de Delpech, Dieulafoy, Oman, Nickerson y Roquebert, las contribuciones de la historiografía catalana (Bofarull, Miret, Soldevila, Dalmau, Ventura) y el estudio de Alvira (2002), aunque su intención era ofrecer una interpretación innovadora de la batalla ${ }^{107}$. Para lograrlo, se alejó de los planteamientos más recientes de Roquebert y Alvira, inspirados en la versión de Dieulafoy, y retomó el de Oman a través de Dalmau ${ }^{108}$. El primer asunto delicado es la ubicación del campamento hispano-occitano. Hernàndez descartó la ubicación al norte-noroeste de Muret y al norte de la elevación de Perramon por estar cerca de las marismas situadas entre el río Loja y el arroyo Aoussaou, muy insalubres en verano. El mismo argumento le valió para no creer viable una posición cerca del Garona. Hernàndez volvió, pues, al emplazamiento al norte de Muret propuesto por Köhler, Oman y Dalmau, situando el campamento muy cerca de Le Petit Jofréry, en un espacio limitado por el arroyo Les Pesquiès al norte, su zona pantanosa al oeste y el camino antiguo de Tolosa y el Garona al este ${ }^{109}$. Esta propuesta es verosímil, ya que cuenta con todas las ventajas militares que, en su momento, apuntaran Köhler, Oman y Mundy: ubicación en la ruta seguida por el grueso del ejército desde Tolosa; ventajas logísticas (espacio, agua, cercanía a las barcazas del Garona); y cercanía al lugar donde en el siglo XIX se localizaron los únicos restos arqueológicos conocidos del campo de batalla ${ }^{110}$. El gran inconveniente de esta interpretación, como ya reconocieran desde el siglo XIX otros autores, es que niega a Guilhem de Puèglaurenç, el único cronista medieval que informó, y con precisión además, de la posición del campamento hispano-occitano.

Hernàndez también quiso ser diferente en la explicación de la batalla e intentó cuadrar el círculo de las impresiones contradictorias que nos dan las fuentes coetáneas: el ejército del rey de Aragón se formó en orden de combate, con el conde de Foix y los catalanes delante y el rey de Aragón con los aragoneses en un segundo cuerpo (Guilhem de Puèglaurenç); estas tropas esperaban en formación el ataque de los cruzados (Pierre des Vaux-de-Cernay); y el rey salió precipitadamente con los suyos de su campamento al ver que atacaban los cruzados (Cansó de la Crozada) ${ }^{111}$. En su opinión, la caballería hispano-occitana formó en orden de combate durante el ataque inicial lanzado contra la Puerta de Tolosa, pero todo el ejército se retiró después al campamento, dejando únicamente un "cuerpo de guardia" delante de las murallas de Muret. Se produjo a continuación el ataque por sorpresa de los cruzados, que forzó la salida precipitada de los hispano-occitanos de su campamento. En este trance, el primer cuerpo del ejército, integrado por el conde de Foix y los catalanes,

106 Hernàndez; Riart; Rubio, El exèrcits, 2009.

107 Hernàndez, Història, pp. 65-83. Repetimos aquí los comentarios que hicimos en Alvira, Muret, 2008, pp. 154-155, 168 y 170-171.

108 Roquebert, L'Épopée, II, pp. 187-236; Alvira, El Jueves, pp. 229-407; y Dalmau, L’heretgia, pp. 55-67.

109 Hernàndez, Història, p. 71.

110 Köhler (1886); Oman (1898 y 1924); y Mundy (1941); también Dalmau (1960).

111 Guilhem de Puèglaurenç, cap. 21, pp. 88 y 90; Pierre des Vaux-de-Cernay, § 462; Cansó, estrofa 140, vv. 1-15. 
no llegó a formar de nuevo en orden de combate. Lo que encontraron los cruzados fue ese "cuerpo de guardia de la caballería aliada" que vigilaba Muret. Al ver que los franceses atacaban, el rey de Aragón llamó a las armas y acudió precipitadamente en su auxilio al frente de los caballeros catalanes, aragoneses y occitanos. Por lo tanto, el segundo cuerpo aragonés que mencionan Vaux-de-Cernay y Puèglaurenç tampoco llegó a formar en orden cerrado durante el combate de caballería ${ }^{112}$.

La batalla de Muret propuesta por Hernàndez es tan interesante como indemostrable. La espera en formación de la caballería hispano-occitana durante el ataque a la Puerta de Tolosa es ciertamente verosímil, pero que el ejército no volviera a formar en orden de combate niega los testimonios de Vaux-de-Cernay y Puèglaurenç. En cuanto a la existencia de ese supuesto "cuerpo de guardia", no hay dato objetivo alguno en ninguna de las fuentes de la batalla que permita corroborarla. La interpretación de Hernàndez sería coherente y verosímil si sólo contáramos con el testimonio de la Cansó de la Crozada. Ojalá fuera así, porque habría evitado a todos los analistas de Muret muchos quebraderos de cabeza. Pero aceptar su propuesta supone rechazar los testimonios de tres fuentes de primera mano: la Carta de los Prelados, la Hystoria Albigensis de Pierre des Vaux-de-Cernay y la Chronica de Guilhem de Puèglaurenç; por no hablar del Llibre dels Feits de Jaime I, que en ningún caso da a entender que la batalla fuera consecuencia de un ataque por sorpresa sobre el campamento hispanooccitano $^{113}$.

El principal problema de la hipótesis de Hernàndez reside justamente en una concepción apriorística y muy personal de las fuentes medievales de la batalla, a partir de la cual elige cuál de ellas le merece confianza y cuáles no. Afirma, primero, que la versión de Vaux-de-Cernay es un relato reinventado para magnificar la verdadera batalla de Muret, que en realidad fue "ràpida, grisa, estúpida i sòrdida". El cronista cisterciense no le merece crédito, porque construyó "una visió políticament correcta de l'enfrontament" con la intención de "deformar la història de la batalla fins ajustar-la a la batalla ideal que haguessin desitjat els croats". En cuanto a la versión de Puèglaurenç, Hernàndez cree que "també resulta tendenciosa". De la Cansó de la Crozada, en cambio, dice que "ofereix una visió força objectiva dels fets" y que "es la fuente más primaria, más fiable y más objetiva sobre Muret" ${ }^{114}$. Pero lo cierto es que no hay razón alguna que avale la fiabilidad y la imparcialidad de la Cansó de la Crozada ${ }^{115}$. $\mathrm{Su}$ autor era tan interesado como Vaux-de-Cernay y tan tendencioso como Puèglaurenç, si es que éste puede ser calificado así y si es que estos adjetivos no valen para todos los escritores medievales. La segunda parte de la Cansó fue escrita en plena guerra contra la Cruzada Albigense como un arma literaria pensada para movilizar a los occitanos en torno al conde Raimon VI de Tolosa y su hijo Raimondet, héroe del poema. La Cansó no puede ser imparcial, porque es el discurso ideológico de uno de los dos bandos enfrentados. Si Vaux-de-Cernay fue un manipulador y Guilhem de Puèglaurenç un tendencioso, otro tanto vale para el poeta anónimo tolosano. Tampo-

\footnotetext{
112 Hernàndez, Història, pp. 75 y 78-80.

113 Carta del preboste Mascaró, en Pierre des Vaux-de-Cernay, vol. III, nº 4, pp. 200-205; y Jaime I, cap.

114 Ibidem, pp. 66-68.

115 Bibliografía al respecto en Alvira, El Jueves, pp. 124-126; y Muret, pp. 379-380.
} 9, pp. 13-14. 
co puede decirse que su versión sea la más primaria, pues fue escrita por alguien que no estuvo en la batalla con informaciones de personas que si lo estuvieron; es decir, lo mismo que las versiones de Vaux-de-Cernay y Puèglaurenç. Por último, sostener que la batalla de Muret ocurrió como dice la Cansó de la Crozada tampoco es nuevo: en el siglo XIX lo creyó el gran historiador tolosano Auguste Molinier y en 1957 lo repitió Jean Léonard Pène ${ }^{116}$. Así pues, la propuesta de F. Xavier Hernàndez, que ciertamente contiene reflexiones y propuestas interesantes y novedosas que animarán el debate sobre el choque de 1213, se sostiene sobre una valoración y una selección de las fuentes que ignora la forma de pensar y de escribir de los poetas y los cronistas medievales ${ }^{117}$.

En el año 2008 se publicó Muret 1213, una versión de El Jueves de Muret de Martín Alvira aligerada de aparato crítico y escrita con la intención de llegar a un público amplio. Lo más novedoso respecto del original fue la incorporación de la bibliografía posterior a 2002, el alejamiento del "poema joglaresc català sobre la batalla de Muret" (postulado por Ferran Soldevila como fuente de Bernat Desclot) en favor de la autoría exclusiva del cronista y un intento de dar respuesta a los debates sobre lo ocurrido en el campo de batalla. Éstos quedaron plasmados - como en el libro de Hernàndez- en varios mapas que muestran las distintas propuestas de los especialistas. En el debe del autor puede ponerse algún error de lectura y no haber explotado los trabajos de Hoffman Nickerson, Jonathan Sumption y, sobre todo, Matthew Strickland ${ }^{118}$.

Las últimas "aportaciones" monográficas a la historiografía de la batalla de Muret tienen bastante en común. Proceden de pseudohistoriadores aficionados con intereses en la guerra medieval, que escriben sin atender a las normas de profesionalidad y hacen un uso abusivo o abiertamente plagiario de los trabajos de otros autores. El primero es un artículo de Alberto Raúl Esteban Rivas publicado en la Revista de Historia Militar $^{119}$. El texto presenta un aparato crítico mínimo, con pocas referencias a otros trabajos y, cuando las hay, sistemáticamente incompletas ${ }^{120}$. El autor no conoce las fuentes, de las que habla de segunda mano ${ }^{121}$. En cuanto al relato de la batalla, es una mezcla confusa de ocurrencias y errores ${ }^{122}$ realizada a partir de ideas tomadas de

116 Molinier, La bataille, p. 427; y Pène, La conquête, p. 159.

117 Hay otros datos que indican un conocimiento superficial del mundo medieval y, en concreto, de la Cruzada Albigense. Por ejemplo, cuando el autor califica a las tropas de Simon de Montfort como "un fanàtic exèrcit croat compost per professionals de la guerra i autèntics assasins, motivats del tot per la seva feina" (Hernàndez, Història, p. 69).

118 Alvira, Muret 1213, pp. 164-174, 278 y 350-359 (mapas). Mala lectura del adjetivo grisius ("blanco") como nombre propio del monje cisterciense anónimo enviado por el rey de Aragón a la corte de Juan Sin Tierra (pp. 87-88).

119 Esteban, La espada, pp. 11-72.

120 Sólo hay 17 referencias a los 47 títulos de la bibliografía, más otras cinco a estudios y fuentes no incluidas en la bibliografía. Las páginas se citan en dos de las 22 referencias.

121 Confunde las dos partes de la Cansó, a la que cree una crónica y un poema épico (pp. 44 y 63, n. 77).

122 Entre otros: el rey de Aragón tomó la idea de organizar una reserva en Las Navas (p. 52); cambió su armadura "tras perder una apuesta de juego" (pp. 16, n. 4 y 67, n. 79); Montfort oraba junto a su confesor (p. 43); relata la batalla a partir de la tardía versión de Las Navas de Desclot (pp. 16, 55 y 60); confunde la "natura de armas" de Jaime I con subordinación al rey (p. 36, n. 41); y dice que los cruzados "buscaban destruir todo aquello que significaba diversidad y libertad espiritual" (p. 69). 
otros autores ${ }^{123}$, principalmente Alvira, al que plagia en varias ocasiones ${ }^{124}$. La confirmación de estas malas artes se observa en un libro electrónico del mismo autor, que no es sino una ampliación del mismo artículo ${ }^{125}$.

El segundo de estos textos, publicado en 2012, es de Rubén Sáez Abad ${ }^{126}$. Forma parte de la colección "Guerreros y Batallas", que aspira a ser una versión española de las publicaciones de Historia Militar de la prestigiosa editorial británica Osprey Military ${ }^{127}$. No estamos en condiciones de evaluar toda la colección, que supera ya los ochenta volúmenes, pero sí podemos decir algo a partir de lo leído en los monográficos dedicados a las batallas de Las Navas de Tolosa ${ }^{128}$ y Muret: más vale que los demás títulos sean otra cosa. El texto de Sáez es una glosa muy resumida, llena de errores y con varios plagios del estudio de Alvira publicado en $2002^{129}$. En cuanto al aparato gráfico, que podría esperarse que diera la talla en una publicación al "estilo Osprey", tampoco está a la mínima altura exigible y repite la práctica del plagio ${ }^{130}$.

A día de hoy, hay que reconocer que Muret es la tercera de las tres grandes batallas de principios del siglo XIII. Las razones de esta última posición son complejas, de diferente orden (histórico, historiográfico, político, ideológico, académico-educativo...) y pueden ser explicadas. Pero lo que conviene recordar con Lawrence W. Marvin es que esto no fue siempre así. En la historiografía militar de finales del siglo XIX y principios del siglo XX (1878-1932), la batalla de Muret rivalizó en importancia con los grandes choques de Hastings y Bouvines ${ }^{131}$. Por eso, llama mucho la atención

123 Delpech, Dieulafoy, Oman, Ventura, Oman, Sumption, Hernàndez y Escura.

124 "La falta de precisión sobre el orden de combate aliado en las fuentes hispano-occitanas podría responder a una falta de información, pero también podría responder a una deliberada ocultación" (p. 50), copiado de Alvira, El Jueves, p. 316: "La falta de precisión sobre el orden de combate catalano-aragonés y occitano en las fuentes hispano-occitanas podría responder a una falta de información. Parece más lógico, sin embargo, que se deba a una deliberada ocultación”. Más ejemplos en pp. 13 (Alvira, El Jueves, pp. 198-209), 17 (pp. 330-331), 28-30 (pp. 285-287 y otros autores tampoco citados), 31 (pp. 340-341), 37 (pp. 232 y 236), 43, n. 47 (p. 253), 44 (pp. 401-403), 55, n. 69 (Alvira, Guerra, I, p. 222), 58 (Alvira, El Jueves, pp. 313-315), 65 (p. 323) y 67 (copiado de Hernàndez, Història, p. 66).

125 "Es por ello que se hace difícil pensar que un hombre con la inteligencia y experiencia militar de Montfort no concibiese algún tipo de acción resolutiva con la que obtener la victoria" (Esteban, La espada, 2009, p. 203), copiado de Alvira, El Jueves, p. 349: "Es difícil no imaginar a un hombre de la inteligencia militar y de la convicción religiosa de Simon de Montfort ordenando, aceptando o ignorando de forma cómplice una maniobra tan decisiva como la de acabar a cualquier precio - capturando o matando-con su principal enemigo en el contexto de la batalla campal"; la prudencia de Montfort (p. 205), copiada de Alvira, El Jueves, p. 355; y el epígrafe titulado "Los pecados del rey" (pp. 123-129), copiado de Alvira, El Jueves, pp. 441-460.

126 Sáez; Antonucci, La batalla, 2012.

127 Catálogo disponible en http://www.ospreypublishing.com. Hay traducción de bastantes títulos.

128 Lago; González, Las Navas, 2005.

129 "Por tanto, la proporción entre aragoneses y cruzados era de 2 a 1; superior, pero no lo suficiente para ser decisiva" (Sáez, p. 59), copiado de Alvira, El Jueves, p. 300: "En consecuencia, la ratio respecto de los cruzados de Simon de Montfort sería de poco más de 2 a 1, una superioridad manifiesta, pero no absoluta, ni mucho menos decisiva"; "siendo privado de sus armas y ropajes por los peones cruzados" (Sáez, p. 63), copiado de Alvira, p. 367: "Había sido privado de sus armas y ropajes por los peones cruzados"; y el traslado del cadáver del rey (Sáez, p. 63, copiado de Alvira, p. 369).

130 Sáez; Antonucci, La batalla, lámina 5, p. 40, copiada de Wise; Scollins, The Knights, figuras B-1 y D-1; e ibidem, lámina 2, p. 34, tomada de Escura; Riart; Garcia, Càtars, pp. 68-69.

131 Marvin, The Occitan War, p. 176. 
que, a estas alturas, el choque de 1213 aún no haya sido totalmente incorporado a la lista natural de batallas del mundo medieval $1^{132}$ o que Muret no termine de ser considerada como una de las grandes batallas de la Historia Militar de España ${ }^{133}$. Esperemos que el interés que pueda suscitar el centenario de este acontecimiento contribuya a corregir estas anomalías.

Para terminar, nos atrevemos a sugerir algunas ideas, por si pudieran ser útiles, a quienes en el futuro se propongan profundizar en este tema. Seguimos pensando que el historiador de la batalla de Muret debe alejarse del marco interpretativo creado en el siglo XIX por la idea de la hermandad de las lenguas occitana y catalana, pues no facilita la comprensión de la compleja situación política de la Francia meridional y la Corona de Aragón de los siglos XII-XIII ${ }^{134}$. En su lugar, convendría aferrarse al contexto histórico medieval y al reflejo de este contexto que es el lenguaje histórico empleado por las fuentes documentales y narrativas de la época ${ }^{135}$. Siempre será inevitable el empleo de términos anacrónicos que son útiles y suficientemente neutros (Corona de Aragón), pero no es lo mismo identificar a las gentes del sur de Francia de lengua provenzal u occitana con el término "occitanos" que hablar de "Occitania" como si fuera una entidad comparable a Francia o, lo que es más habitual, a Cataluña ${ }^{136}$. También sería conveniente evitar la tradicional tendencia a identificar el todo (Corona de Aragón) con las partes (Cataluña o Aragón). Debería reconocerse a los monarcas catalano-aragoneses -Ramón Berenguer IV, Alfonso el Trovador o el Casto, Pedro el Católico- su condición de soberanos de la Corona de Aragón y no del reino de Aragón o del condado de Barcelona o Cataluña por separado, muy especialmente cuando de lo que se habla es de la expansión ultrapirenaica, de la Cruzada Albigense y de la batalla de Muret, esto es, de lo que hoy llamaríamos la "política exterior" de la monarquía catalano-aragonesa ${ }^{137}$. Estas querencias que comentamos son aún visibles en una parte de la historiografía tradicional y en la divulgativa, aun-

${ }^{132}$ No aparece en los libros divulgativos de DeVries et al., Batallas, 2012 (orig. 2006); Frediani, Le grandi battaglie, 2006; y Grandes Batallas, 2009.

133 Ausente en Vázquez y Molina, Grandes batallas, 2010; y en Ladero (coord.), Historia, 2010.

${ }^{134}$ Una buena muestra de esta perspectiva exclusivamente occitano-catalana en el prólogo a Figueres (coord.), Col·loqui, pp. 5-6.

${ }^{135}$ Por ejemplo, denominando a Pedro el Católico "rey de Aragón y conde de Barcelona", tal como aparece en la documentación medieval, en lugar de "comte-rei" o el más reciente "señor-rey" (Bisson, La crisis, pp. 421 y 573-576).

136 El título general de la obra dirigida por Ferrer y Riu alude a las relaciones de Cataluña y la Corona catalano-aragonesa con "Occitània" y "França" (Tractats, 2009). Obsérvese, sin embargo, que las contribuciones de los especialistas llevan títulos ajustados a la realidad histórica (Benito: L'expansió territorial ultrapirinenca de Barcelona i de la Corona d'Aragó; y Ferrer, Les relacions del comtat de Barcelona i de la Corona catalanoaragonesa ambs els estats italians en els segles XI-XII). Un ejemplo de la historiografía anglosajona en Marvin, quien alude varias veces al "people of Occitania" (The Occitan War, pp. 108, 131, $217,235,262,296$ y 301$)$.

137 Tendencias visibles en la forma de llamar a los reyes: Pedro II de Aragón/Pere I de Catalunya o Barcelona; rei català/rey aragonés. El caso del citado Lawrence W. Marvin, un buen historiador, es significativo: se refiere al "kingdom of Aragon", sin apreciar los problemas de esta denominación frente a la de "Crown of Aragon", pero habla luego de los "count-kings" y catalaniza los nombres de los reyes -"Pere II" y "Jaume of Aragon"- e incluso del ricohombre aragonés Miguel de Luesia "Miquel of Luesia" (The Occitan War, pp. 7, $181,192,193$ y 306$)$. 
que hay que reconocer a los especialistas con una producción más reciente el mérito de estar cambiando las cosas ${ }^{138}$.

Hablando de la "política exterior" catalano-aragonesa, hay que insistir en que la batalla de Muret tuvo unas dimensiones "internacionales" que no siempre han sabido reconocerse. Cuando Pedro el Católico atravesó los Pirineos, contaba con unas ventajas estratégicas y unos apoyos exteriores que son incomprensibles ignorando el tenso escenario político europeo de los años 1212-1214 que culminaría en la batalla de Bouvines. Estamos pensando en esas interesantísimas negociaciones secretas entre Pedro el Católico, el conde de Tolosa Raimon VI y el rey de Inglaterra Juan Sin Tierra que aún merecen un análisis más detenido (siempre que las fuentes inglesas puedan darnos algo más de luz al respecto) ${ }^{139}$.

Aquí hemos visto que los debates sobre el desarrollo táctico de la batalla continúan vivos. Sería muy deseable que la Arqueología hiciera por fin acto de presencia. No ha habido, que sepamos, prospecciones o excavaciones orientadas a esclarecer los hechos. Ciertamente, el campo de batalla está hoy muy transformado por las infraestructuras modernas que rodean Muret y Toulouse, y quizá no sea posible una investigación arqueológica en condiciones. Pero sin los datos proporcionados por los arqueólogos, será muy difícil que los historiadores puedan llegar a plantear otra cosa que no sean meras hipótesis.

Hasta que estos datos lleguen, si es que llegan, siempre será posible sugerir nuevas respuestas a las grandes preguntas que plantea el choque de 1213: si el rey de Aragón quería o no librar una batalla campal y desde cuándo; por qué no espero los refuerzos que estaban de camino; dónde estaba el campamento hispano-occitano; cómo y por dónde se produjo la salida de los cruzados de Muret; cómo se llevó a cabo el movimiento de flanqueo del tercer haz de Simon de Montfort y contra qué objetivo; cómo murió Pedro el Católico y si fue reconocido o no por sus enemigos; o cuál fue el verdadero papel de los condes occitanos en la batalla. Muchas de estos interrogantes tienen que ver con la forma de concebir la batalla. Para unos autores fue una especie de refriega rápida producto de una salida inesperada de los cruzados. Quienes la interpretan así tienden a infravalorar las capacidades militares del rey de Aragón, resaltando sus errores tácticos, o a salvar la cara de Pedro el Católico, insistiendo en el factor sorpresa y en la falta de preparación del ejército hispano-occitano. Otros autores, en cambio, han querido ver en Muret una batalla campal en toda regla, incluso si los caballeros catalanes, aragoneses y occitanos formaron sobre el campo rápidamente $\mathrm{y}$, en palabras de Jaime I, no saberen rengar la batayla ni anar justats, $e$ ferien cada un rich hom per si e ferien contra natura d'armes ${ }^{140}$.

La interpretación del desastre de Muret que hizo el hijo de Pedro el Católico nos lleva a hablar de un último campo de estudio en el que casi todo está aún por hacer. Nos referimos a la historia de la guerra en el ámbito de la Corona de Aragón plenomedieval. La idea no es nueva. En 1999, Rachel L. Noah terminaba su tesis doctoral sugiriendo que las futuras investigaciones sobre la Cruzada Albigense deberían insistir en la comparación con los sistemas militares y las prácticas bélicas existentes

\footnotetext{
${ }^{138}$ Como puede apreciarse en los trabajos de Pere Benito y Stefano M. Cingolani.

139 Alvira, Después, pp. 96-102, esp. 98-101.

140 Jaime I, cap. 9, p. 14.
} 
en los territorios vecinos del sur de Francia, "particularly the areas of Aragon and Catalonia"141. Los libros de F. Xavier Hernàndez son un intento en este sentido, si bien desde una perspectiva divulgativa, una óptica principalmente catalana y un ánimo que no aspira a ir más allá de los testimonios de las fuentes narrativas y una bibliografía reducida. Lo cierto es que la importancia enorme de la guerra en la historia catalano-aragonesa de los siglos XI-XIII sigue sin corresponderse con el desarrollo de una investigación académica, específica en este campo y de amplio espectro. Algún día habrá que poner en marcha esa "nueva historia militar" de la Corona de Aragón plenomedieval - una historia moderna, atenta a las metodologías más innovadoras e interesada en la comparación con otros espacios bélicos, tanto hispanos como europeos- que hace unos pocos años demandaba el medievalista José Ángel Sesma y que sigue siendo una tarea pendiente ${ }^{142}$.

\section{BIBLIOGRAFÍA CITADA}

Alvira CABrer, Martín, Guerra e ideología en la España medieval: cultura y actitudes históricas ante el giro de principios del siglos XIII-Batallas de Las Navas de Tolosa (1212) y Muret (1213)-, Tesis Doctoral, dir. Emilio Mitre Fernández, Madrid, Universidad Complutense de Madrid, 2000.

Alvira CABrer, Martín, 12 de Septiembre de 1213. El Jueves de Muret, Barcelona, Vicerectorat d'Arts, Cultura i Patrimoni-Universitat de Barcelona, 2002.

Alvira CABrer, Martín, Le Jeudi de Muret : aspects idéologiques et mentaux de la bataille de 1213, en Roquebert (dir.), La Croisade albigeoise, pp. 197-207.

Alvira CABrer, Martín, “Le jugement de Dieu punit le roi d'Aragon”. La bataille de Muret (12 septembre 1213), en Albaret, Laurent; Gouzy, Nicolas (dirs.), Les grandes batailles méridionales, 1209-1271, Toulouse, Privat, 2005, pp. 73-82.

Alvira Cabrer, Martín, Del "Sepulcro" y los "sarracenos meridionales" a los "herejes occidentales". Apuntes sobre tres "guerras santas" en las fuentes del sur de Francia (Siglos XI-XIII), en Baloup, Daniel; Josserand, Philippe (eds.), Regards croisés sur la guerre sainte. Guerre, religion et idéologie dans l'espace méditerranéen latin (XIe-XIII siècle), Toulouse, CNRS-Université de Toulouse II-Le Mirail, 2006 (Collection Méridiennes-Série Études Médiévales Ibériques), pp. 187-229.

Alvira Cabrer, Martín, Muret 1213. La batalla decisiva de la Cruzada contra los Cátaros, Barcelona, Ariel, 2008 (Grandes Batallas); reed. 2013 (Ariel Historia).

Alvira CAbrer, Martín; Macé, Laurent; Smith, Damian J., Le temps de la "Grande Couronne d'Aragon" du roi Pierre le Catholique. À propos de deux documents relatifs à l'abbaye de Poblet (février et septembre 1213), "Annales du Midi. Revue de la France Méridionale", 121-265 (Janvier-Mars 2009), pp. 5-22.

Alvira CABrer, Martín, La Cruzada contra los Albigenses: historia, historiografía y memoria, "Clío \& Crimen", 6 (2009), pp. 110-141.

Alvira Cabrer, Martín, Pedro el Católico, Rey de Aragón y Conde de Barcelona (11961213). Documentos, Testimonios y Memoria Histórica [en línea], 6 vols., Zaragoza, Insti-

141 Noah, Military Aspects, p. 139.

142 Sesma, Guerra, pp. 13-19, esp. 17 y 19. En relación con este tema, Alvira, Historiografía (en prensa). 
tución Fernando el Católico, 2010 (Fuentes Históricas Aragonesas, 52), http://ifc.dpz.es/ publicaciones/ebooks/id/3003 [fecha de consulta: 05/10/2012].

Alvira Cabrer, Martín, Después de Las Navas de Tolosa y antes de Bouvines. La batalla de Muret (1213) y sus consecuencias, en 1212-1214: el trienio que hizo a Europa. Actas de la XXXVII Semana de Estudios Medievales de Estella (19 al 23 de julio de 2010), Pamplona, Gobierno de Navarra, 2011, pp. 85-111.

Alvira Cabrer, Martín, Las Navas de Tolosa, 1212. Idea, liturgia y memoria de la batalla, Madrid, Sílex, 2012.

Alvira Cabrer, Martín, Itinerarios entre batallas. Los desplazamientos de Pedro el Católico, rey de Aragón y conde de Barcelona, de julio de 1212 a septiembre de 1213, "De Medio Aevo", 1 (2013), en prensa.

Alvira Cabrer, Martín, Historiografía de la guerra medieval: la Corona de Aragón (siglos XI-XIII), en Actas del I Symposium Internacional "La Conducción de la Guerra (9501350): Historiografía” (Cáceres, 18-20 de Noviembre de 2008), Cáceres, Universidad de Extremadura (en prensa).

Alvira Cabrer, Martín, El rey de Aragón Pedro el Católico y sus batallas: del triunfo de Las Navas de Tolosa al desastre de Muret, en Salvatierra, Vicente; Cressier, Patrice; Castillo, Juan Carlos (eds.), Miradas Cruzadas. Las Navas de Tolosa, 1212-2012, Jaén, Universidad de Jaén (en prensa).

Amado, Claudie, À l'origine des liens entre la Catalogne et l'Occitanie méditerranéenne (800-1200), en Figueres (coord.), Col-loqui, pp. 81-108.

Anglade, Jean, La bataille de Muret (12-septembre-1213) d'après la Chanson de la Croisade, Toulouse, Privat, 1913 (reed. 2002).

Aurell, Martin, Les sources de la Croisade albigeoise : bilan et problématiques, en Roquebert (dir.), La Croisade albigeoise, pp. 21-38.

Aurell, Martin (dir.), Les cathares devant l'Histoire. Mélanges offerts à Jean Duvernoy, ed. Anne Brenon; Christine Dieulafait, Cahors, L'Hydre, 2005.

Au temps de la Croisade. Société et pouvoirs en Languedoc au XIII siècle. Exposition réalisé par les Archives départementales de l'Aude (Carcassonne, 17 septembre-28 novembre 2009), Carcassonne, Conseil général de l'Aude, 2009.

Au temps de la Croisade. Société et pouvoirs en Languedoc au XIII siècle. Acte des conférences et tables rondes tenues dans l'Aude (3 avril-20 octobre 2009), Carcassonne, Conseil général de l'Aude, 2010.

Aventin, Mercè, Relacions catalano-occitanes i expansió ultrapirenaica (segle XII), en El Somni d'Occitània. Vuitè centenari d'Alfons el Cast, primer rei de Catalunya-Aragó (1154-1196), Barcelona, Fundació Jaume I, 1996, pp. 23-38.

BALoup, Daniel, La Croisade albigeoise dans les chroniques léonaises et castillanes du XIII siècle, en Roquebert (dir.), La Croisade albigeoise, pp. 91-107.

Belperron, Pierre, La Croisade contre les Albigeois et l'union du Languedoc à la France, 1200-1249, París, Plon, 1942 (2ª . ed. París, Perrin, 1967).

Benito i Monclús, Pere, La submissió del comte Hug IV d’Empúries i de la noblesa emporitana a l'Església de Girona (1226-1229): una repercussió de la croada albigesa liderada per Lluís VIII, rei de França, a Catalunya, en Plans, Lourdes (ed.), Església, societat $i$ poder a les terres de parla catalana. Actes del IV Congrès de la CCEPC (Vic, 20 i 21 de febrer de 2004), Valls, Coordinadora de Centres d'Estudis de Parla Catalana Institut Ramon 
Muntaner-Universitat de Vic-Cossetània Edicions, 2005 (Publicacions de la Coordinadora de Centres d'Estudis de Parla Catalana, 3), pp. 139-154.

Benito i Monclús, Pere, L'expansió territorial ultrapirinenca de Barcelona i de la Corona d'Aragó: guerra, política i diplomàcia (1067-1213), en Ferrer; Riu (dirs.), Tractats, pp. 13-150.

Bennett, Matthew; Bradbury, Jim; DeVries, Kelly; Dickie, Ian; Jestice, Phyllis G., Técnicas bélicas del mundo medieval, 500 a.C-1500 d.C. Equipamiento, Técnicas y Tácticas de combate, Madrid, Libsa, 2007 (orig. Londres, Amber Kooks, 2005).

BIsson, Thomas N., La crisis del siglo XII. El poder, la nobleza y los orígenes de la gobernación de Europa, Barcelona, Crítica, 2010 (orig. Princeton, Princeton University Press, 2009).

Blasco Vallés, Almudena, Gastó VI de Bearn i Montcada i la Croada, en Figueres (coord.), Col·loqui, pp. 141-156.

Bourin, Monique (dir.), En Languedoc au XIII siècle. Le temps du sac de Béziers. Actes des $X X^{e}$ rencontres de Béziers organisés par URBI [Université et Recherche en Biterrois] (4-5 juin 2009), Perpiñán, Presses Universitaires de Perpignan, 2010.

Bradbury, Jim, Medieval Warfare (The Routledge Companion to), Oxon, Routledge, 2006.

Cansó de la Crozada. Continuación anónima, ed. y trad. fr. Eugène Martin-Chabot, vol. II, París, Les Belles Lettres, 1957 (Les Classiques de l'Histoire de France au Moyen Age, 24).

Càtars i trobadors. Occitània i Catalunya: renaixença i futur (Museu d'Història de Catalunya, 5 d'abril-27 de juliol de 2003), Barcelona, Museu d'Història de Catalunya-Generalitat de Catalunya, 2003.

Cavazzocca-Mazzanti, Karin, La Croisade albigeoise vue par Robert de Saint-Marien d'Auxerre, en Roquebert (dir.), La Croisade albigeoise, pp. 55-69.

Chronique dite de Baudoin d'Avesnes, ed. fragmentaria en Dévic, Claude; Vaissète, Joseph, Histoire générale de Languedoc (ed. Auguste Molinier), Toulouse, Privat, vol. VII (1879), nota 17 , pp. 52-54.

Cingolani, Stefano M., Historiografia, propaganda i comunicació al segle XIII: Bernat Desclot $i$ les dues redaccions de la seva crònica, Barcelona, Institut d'Estudis Catalans, 2006.

Cingolani, Stefano M., Jaume I. Història i mite d'un rei, Barcelona, Edicions 62, 2007 (trad. Barcelona, Edhasa, 2009).

Cingolani, Stefano M., La memòria dels reis. Les quatre grans cròniques i la historiografia catalana, des del segle X fins al XIV, Barcelona, Base, 2007.

Cingolani, Stefano M. (ed.), Gestes dels Comtes de Barcelona i Reis d'Aragó, Valencia, Universitat de València, 2008 (Monuments d'Història de la Corona d'Aragó, 1).

Cingolani, Stefano M. (ed.), Libre dels reis, Valencia, Universitat de València, 2008 (Monuments d'Història de la Corona d'Aragó, 2).

Cingolani, Stefano M. (ed.), Els annals de la família Rivipullense i les genealogies de Pallars-Ribagorça, Valencia, Universitat de València, 2012 (Monuments d'Història de la Corona d'Aragó, 3).

Cingolani, Stefano M. (ed.), Les “Gesta Comitum Barcinonensium” (versió primitiva), la "Brevis historia" $i$ altres textos de Ripoll, Valencia, Universitat de València, 2012 (Monuments d'Història de la Corona d'Aragó, 4). 
Cingolani, Stefano M.; Álvarez Masalias, R. (eds.), Gestes dels Comtes de Barcelona i Reis d'Aragó. Gesta Comitum Barchinone et Regum Aragoniae, Santa Coloma de Queralt, Obrador Edèndum, 2012.

Contamine, Philippe, Le Jeudi de Muret, 12 septembre 1213, le Dimanche de Bouvines, 27 juillet 1214 ; deux “journées" qui ont "fait la France”?, en Roquebert (dir.), La Croisade albigeoise, pp. 109-123.

Crusafont i Sabater, Miquel, Història de la moneda de l'Occitània catalana (s. XI-XIII), Barcelona, Societat Catalana d'Estudis Numismàtics (Institut d'Estudis Catalans), 2012.

Dalmau i Ferreres, Rafael, L'heretgia albigesa i la batalla de Muret, Barcelona, Rafael Dalmau, 1960 (Episodis de la Història, 8).

Dalmau i Ribalta, Antoni, El triunfo de los cruzados. La batalla de Muret, "Historia National Geographic", 33 (2006), pp. 80-91.

DÉBAX, Hélène, La féodalité languedocienne, XIe-XII siècles, Toulouse, Presses Universitaires du Mirail, 2003.

DÉBAx, Hélène, El fracàs de l'Estat occità. Les divergències de l'evolució entre Occitània i Catalunya (segles IX-XIII), en Càtars i trobadors, pp. 68-75.

Delbrück, Hans, Geschichte der Kriegskunst im Rahmen der politischen Geschichte, 4 vols., Berlín, 1900-1920 (trad. ing. History of the Art of War Within the Framework of Political History. Volume III: The Middle Ages, Londres-Westport, Greenwood Press, 1982).

DelPech, Henri, La bataille de Muret et la tactique de la cavalerie au XIII siècle, ParísToulouse-Montpellier, A. Picard-Duclos-H. Delpech y Société pour l'Étude des Langues Romanes, 1878; reed. La tactique au XIII ${ }^{\text {me }}$ siècle, 2 vols., París, A. Picard, 1886, I, pp. 177-265.

DelPeCh, Henri, Un dernier mot sur la bataille de Muret, Montpellier, Imprimerie Firmin et Cabirou, 1878, pp. 1-16.

Dévoluy, Pierre, La Bataio de Muret, "Vivo Prouvènço", 33 (7 septiembre 1907).

DeVries, Kelly; Dougherty, Martin; Dickie, Ian; Jestice, Phyllis G.; Jorgersen, Christer, Batallas Medievales, 1000-1500, Madrid, Tikal, 2012 (orig. Nueva York, Barnes \& Noble, 2006).

Dieulafoy, Marcel, La bataille de Muret, "Mémoires de l'Institut nationale de France. Académie des Inscriptions et Belles Lettres", 36-2 (1899-1901), pp. 95-134.

Escura i Dalmau, Xavier; Riart i Jou, Francesc; Garcia i Quera, Oriol, Càtars i trobadors. Un viatge il·lustrat a l'Occitània del segle XIII, Barcelona, Signament, 1998.

Escura i Dalmau, Xavier, Els mites de Muret i Montsegur, Barcelona, Rafael Dalmau, 2003 (Episodis de la Història, 338).

Espalader, Antoni M., El casal de Barcelona i la poesia trobadoresca, en Càtars $i$ trobadors, pp. 106-123.

Esteban Rivas, Alberto Raúl, La espada y la cruz. La batalla de Muret, "Revista de Historia Militar”, 104 (2008), pp. 11-72 (y publicación electrónica ampliada, 2009).

Evans, Austin P., The Albigensian Crusade, en Setton, Kenneth M. et al. (dir.), A History of the Crusades, Philadelphia, University of Pennsylvania Press, 1962, pp. 277-324.

Ferrer i Mallol, Maria Teresa; Riu i Riu, Manuel (dirs.), Tractats i negociacions diplomàtiques de Catalunya i de la Corona catalanoaragonesa a l'edat mitjana. Vol. I.1: Tractats i negociacions diplomàtiques amb Occitània, França i els estats italians, 1067-1213, Barcelona, Institut d'Estudis Catalans, 2009 (Memòries de la Secció Històrico-Arqueològica, 83). 
Figueres, Josep M. (coord.), Col-loqui d'Història Medieval Occitano-Catalana, El Prat de Llobregat-Barcelona, Eurocongrés2000-Fundació Occitanocatalana, 2004.

France, John, Western Warfare in the Age of the Crusades, 1000-1300, Ithaca-Nova Iorque, Cornell University Press, 1999.

France, John, A Changing Balance: Cavalry and Infantry, 1000-1300, "Revista de História das Ideias", 30 (2009), pp. 153-177.

Frediani, Andrea, Le grandi battaglie del Medioevo, Roma, Newton Compton, 2010 (1 ${ }^{\mathrm{a}}$. ed. 2006).

Galey, Simmone; Bonnet, Alain, 12 septembre 1213. Muret, la bataille, Muret, Office de Tourisme, 2005.

García Fitz, Francisco, Las Navas de Tolosa, Barcelona, Ariel, 2005.

García Fitz, Francisco, La batalla en la Edad Media: algunas reflexiones, "Revista de Historia Militar", 100 (2006), pp. 93-108.

Gasc, Jean-Louis, La bataille de Muret, "Pyrénées Cathares Magazine”, (été 2003), pp. 8290.

Grandes Batallas de la Historia. Canal Historia, Madrid, Plaza \& Janés, 2009.

Grau, Sergi, Catarismo e Inquisición en los reinos hispánicos (siglos XII-XIV), Madrid, Cátedra, 2012.

Guida, Saverio, Pietro il Cattolico ed i trovatori, en Beltrán Pepió; Vicente; Simó, Meritxell; Roig, Elena (eds.), Trobadors a la Península Ibérica. Homenatge al Dr. Martí de Riquer, Abadía de Montserrat, 2006, pp. 223-240.

Guilhem de Puèglaurenç (Guillaume de Puylaurens), Chronica Magistri Guillelmi de Podio Laurentii, ed. y trad. fr. Jean Duvernoy, Toulouse, Pérégrinateur, 1996.

Hernàndez, Francesc Xavier, Història Militar de Catalunya. Vol. II: Temps de conquesta, Barcelona, Rafael Dalmau, 2002.

Hernàndez, Francesc Xavier; Riart, Francesc; Rubio, Xavier, El exèrcits de Jaume I, Barcelona, Duxelm, 2009 (Polemos, 1).

Jaime I el Conquistador, Llibre dels Fets del Rei En Jaume, ed. Jordi Bruguera, 2 vols., Barcelona, Barcino, 1991.

JimÉnEz SÁnchez, Pilar, Les catharismes. Modèles dissidents du christianisme médiéval, Rennes, Presses Universitaires de Rennes, 2008.

KöHLER, Gustav, Die Entwickelung des Kriegswesens und der Kriegführung in der Ritterzeit, 3 vols., Breslau, W. Koebner, 1886-1889.

Kovarik, Robert J., Simon de Montfort (1165-1218), His Life and Work. A Critical Study and Evaluation Based on the Sources, Ann Arbor, Saint Louis University, 1963.

LABORIE, Florent, Les itinéraires du roi Pierre II d'Aragon (1196-1213) : tentative d'approche cartographique, 2 vols., Mémoire de maîtrise, dir. Laurent Macé, Toulouse, Université de Toulouse-Le Mirail, 2005.

Ladero Quesada, Miguel Ángel (coord.), Historia Militar de España dirigida por Hugo O’Donnell. II. Edad Media, Madrid, Laberinto-Ministerio de Defensa, 2010.

Lago, José Ignacio; González Pérez, Manuel, Las Navas de Tolosa 1212: la verdadera cruzada, Madrid, Almena, 2005 (Guerreros y batallas, 33).

Losada, Juan Carlos, Batallas decisivas de la Historia de España, Madrid, Aguilar, 2004.

Lot, Ferdinand, L'art militaire et les armées au Moyen Age, 2 vols., París, Payot, 1946. 
MACÉ, Laurent, Les comtes de Toulouse et leur entourage. Rivalités, alliances et jeux de pouvoir, XII ${ }^{e}$-XIII ${ }^{e}$ siècles, Toulouse, Privat, 2000 (reed. 2003).

Macé, Laurent (coord.); Aurell, Martin; García Fitz, Francisco; Sabaté, Flocel; Sarasa SÁnChez, Esteban; Alvira CABrer, Martín, "Muret, Muret, Muret Morne Plaine!'. Réflexions sur "El Jueves de Muret" de Martín Alvira Cabrer, "Heresis", 41 (Automne-Hiver 2004), pp. 13-54.

MacÉ, Laurent, Catalogues raimondins (1112-1229). Actes des comtes de Toulouse, ducs de Narbonne et marquis de Provence, Toulouse, Archives Municipales, 2008 (Sources de l'Histoire de Toulouse, 1).

Macé, Laurent, “Viator rex”. Sur les pas de Pierre II d'Aragon, “e-Spania” [en línea], 8 (décembre 2009), DOI: 10.4000/e-spania.18649.

Martel, Philippe, Les cathares et l'Histoire. Le drame cathare devant ses historiens (18201992), Privat, Toulouse, 2002.

Martel, Philippe, El Jocs Florals, el Felibritge i la Renaixença, en Càtars i Trobadors, pp. 194-201.

Marvin, Lawrence W., The Occitan War. A Military and Political History of the Albigensian Crusade, 1209-1218, Cambridge, Cambridge University Press, 2008.

Marvin, Lawrence W., Muret, Battle of, en Rogers, Clifford J. (dir.), The Oxford Encyclopedia of Medieval Warfare and Military Technology, 3 vols., Nueva York, Oxford University Press, 2010, vol. I, pp. 36-37.

Meschini, Marco, Battaglie medievali, Milán, Società Europea di Edizioni, 2005 (Il GiornaleBiblioteca Storica, 24).

Meschini, Marco (coord.); Alvira Cabrer, Martín; Aurell, Martin; Macé, Laurent; Smith, Damian J.; Wagner, Kay, Bibliografia delle Crociate Albigesi, "Reti Medievali. Rivista", 7-1 (2006), DOI: 10.6092/1593-2214/173.

Meschini, Marco, “Pro negotio crucesignatorum”. Innocenzo III e il sostegno della guerra santa, en Baloup, Daniel; Josserand, Philippe (eds.), Regards croisés sur la guerre sainte. Guerre, religion et idéologie dans l'espace méditerranéen latin (XI'-XIII' siècle), Toulouse, CNRS-Université de Toulouse II-Le Mirail, 2006 (Collection Méridiennes-Série Études Médiévales Ibériques), pp. 159-186.

Meschini, Marco, Innocenzo III e il "negotium pacis et fidei" in Linguadoca tra il 1198 e il 1215, "Atti della Academia Nazionale dei Lincei”, 20-2 (2007), pp. 365-906.

Meschini, Marco, L'eretica. Storia della Crociata contro gli albigesi, Bari, Laterza, 2010.

Molinier, Auguste, La bataille de Muret d'après les chroniques contemporaines, en Dévic, Claude; Vaissète, Joseph, Histoire générale de Languedoc (ed. Auguste Molinier), Toulouse, Privat, vol. VII (1879), nota 48, pp. 254-259.

Monteiro, João Gouveia, Estratégia e risco em Aljubarrota: a decisão de dar batalha à luz do "Paradigma Gillingham", en idem, Entre romanos, cruzados e ordens militares. Ensaios de História militar antiga e medieval, Coimbra, Salamandra, 2010, pp. 137-168.

MonteIro, João Gouveia, A arte militar na Europa dos seculos XI-XIII -um “vade mecum”, "Revista de História das Ideias", 32 (2011), pp. 7-49.

Moore, Robert, Les Albigeois d'après les chroniques angevines, en Roquebert (dir.), La Croisade albigeoise, pp. 81-90.

Moore, R. I., The War "on" Heresy. Faith and Power in Medieval Europe, Londres, Profile Books, 2012. 
Mundó, Anscari M., Catalunya i Occitània: les primeres relacions històriques, en Figueres (coord.), Col·loqui, pp. 9-24.

Mundy, John Hine, The Albigensian Crusade, 1209-1229. A Military Study, M.A. Dissertation submitted in partial fulfilment of the requirements for the degree of Master of Arts in the Faculty of Political Science, dir. Austin P. Evans, Nueva York, Columbia University, 1941.

Nickerson, Hoffman, Warfare in the Roman Empire, the Dark and Middle Ages, en Spaulding, Oliver Lyman Jr.; Nickerson, Hoffman; Wright, John Womack, Warfare. A Study of Military Methods From the Earliest Times, Nueva York, Harcourt Brace, 1925, pp. 191-411 (reed. Nueva York, Dover, 2003).

Nickerson, Hoffman, Oman's Muret, “Speculum”, 6 (1931), pp. 550-572.

Nickerson, Hoffman, The Inquisition. A Political and Military Study of its Establishment, $2^{\mathrm{a}}$ ed., Boston-Nueva York, Houghton Mifflin Company, 1932 (1 ${ }^{\mathrm{a}}$. ed. Londres, John Bale, sons, \& Danielsson, 1923; trad. La Inquisición y el genocidio del pueblo cátaro, Barcelona, Círculo Latino, 2005).

Nicolle, David; Hook, Adam, European Medieval Tactics (1). The Fall and Rise of Cavalry 450-1260, Oxford-Nueva York, Osprey Publishing, 2011.

NoAH, Rachel Louise, Military Aspects of the Albigensian Crusade, Thesis submitted to the Department of Medieval History in fulfilment of the degree of Master of Philosophy, dir. Matthew Strickland, Glasgow, University of Glasgow, 1999.

Odalric de Caixal i Mata de Armagnac, David, La batalla de Muret. 13 de setiembre [sic] de 1213, "Arqueología, historia y viajes sobre el mundo medieval", 40 (2011), pp. 58-65.

Oman, Charles, A History of the Art of War. The Middle Ages, from the Fourth to the Fourteenth Century, Nueva York-Londres, G.P. Putnam's Sons-Methuen, 1898; $2^{\text {a }}$ ed. A History of the Art of War in the Middle Ages, Vol. I: A.D. 378-1278, Londres, Methuen, 1924.

PEgG, Mark Gregory, A Most Holy War. The Albigensian Crusade and the Battle for Christendom, Oxford-Nueva York, Oxford University Press, 2008.

PÈnE, Jean Léonard, La conquête du Languedoc : essai de critique et d'histoire, Niza, Gimello, 1957.

Riera Melis, Antoni, La desvinculació d'Occitània de la Corona Catalanoaragonesa (12081349), en Figueres (coord.), Col·loqui, pp. 57-80.

Rodríguez Bernal, Francesc, L'alta noblesa de Catalunya i la primera expansió catalana sobre el Midi (1112-1144), en Figueres (coord.), Col·loqui, pp. 157-172.

Roquebert, Michel, L’Épopée cathare, 5 vols, Toulouse, Privat, 1970, 1977, 1986, 1989 y París, Perrin, 1998 (reed. 2 vols., París, Perrin-Privat, 2001; reed. 5 vols., París, Perrin, 2007-2008).

Roquebert, Michel (dir.), La Croisade albigeoise. Actes du Colloque International du Centre d'Études Cathares (Carcassonne, 4-6 octobre 2002), Balma, Centre d'Études Cathares, 2004 (Heresis, $\mathrm{N}^{\mathrm{o}}$ Extraordinaire).

Roquebert, Michel, Simon de Montfort, bourreau et martyr, París, Perrin, 2005.

Sáez Abad, Rubén; Antonucci, Claudio, La batalla de Muret, 1213, Madrid, Almena, 2012 (Guerreros y Batallas, 80).

SAlRach, Josep Maria, Relacions catalano-occitanes i expansió ultrapirenaica (segle XI), en El Somni d'Occitània. Vuitè centenari d'Alfons el Cast, primer rei de Catalunya-Aragó (1154-1196), Barcelona, Fundació Jaume I, 1996, pp. 12-22. 
Sella, Antoni; Fernández, Jaume; Passolas, Enric; Garcia Quera, Oriol, 1213. La batalla de Muret. La gran derrota catalana, "Sàpiens", 32 (2005), pp. 24-31.

Sesma Muñoz, José Ángel, Guerra, ejército y sociedad en los reinos de Aragón y Navarra en la Edad Media, "Revista de Historia Militar. Núm. Extraordinario 1: Historia Militar: Métodos y recursos de investigación" (2002), pp. 13-47.

Smith, Damian J., Peter II, Innocent III and the Albigensian Crusade, en Sommerlechner, Andrea (ed.), Innocenzo III: Urbs et Orbis. Atti del Congresso Internazionale Roma, 9-15 settembre 1998, Roma, Istituto storico Italiano per il medio evo, 2003 (Nuovi studi storici 55 - Miscellanea della Società Romana di storia patria, 44), pp. 1.049-1.064.

Smith, Damian J., Aragon, Catalogne et la Papauté pendant la Croisade contre les Albigeois, en Roquebert (dir.), La Croisade albigeoise, pp. 157-170.

Smith, Damian J., Innocent III and the Crown of Aragon. The Limits of Papal Authority, Aldershot, Ashgate, 2004.

Smith, Damian J., Crusade, Heresy and Inquisition in the Lands of the Crown of Aragon (c. 1167-1276), Boston, Brill, 2010 (The Medieval and Early Modern Iberian World, 39).

SoulA, René, Les cathares entre légende et histoire. La mémoire de l'albigéisme du XIXe siècle à nos jours, Bouloc, Institut d'Études Occitans, 2005.

Strayer, Joseph R., The Albigensian Crusades, Nueva York, Dial Press, 1971.

Strickland, Matthew, War and Chivalry. The Conduct and Perception of War in England and Normandy, 1066-1217, Cambridge, Cambridge University Press, 1996.

Strickland, Matthew, Provoking or Avoiding Battle? Challenge, Duel and Single Combat in Warfare of the High Middle Ages, en idem (ed.), Armies, Chivalry and Warfare in Medieval Britain and France, Stamford, Paul Watkins, 1998 (Harlaxton medieval studies. New series, 7), pp. 317-343.

Sumption, Jonathan, The Albigensian Crusade, Londres-Boston, Faber \& Faber, 1978.

Vaux-De-Cernay, Pierre des, Hystoria Albigensis, ed. P. Guébin; E. Lyon, 3 vols., París, H. Champion, 1926-1930.

Vázquez García, Juan; Molina Franco, Lucas, Grandes batallas de España, Madrid, Tikal, 2010.

Vélez, Antonio R., Muret ¿adiós al país de los Pirineos?, “Clío. Especial 800 años de la Cruzada contra los Cátaros ¿Rebeldes con causa?”, (abril 2009), pp. 94-95.

Ventura, Jordi, Pere el Catòlic i Simó de Montfort, Barcelona, Aedos, 1960 (Bibliografía Biográfica Aedos, 24); 2a ed. Barcelona, Selecta-Catalònia, 1996 (Col·lecció Antílop, 41).

Verbruggen, Johan F., The Art of Warfare in Western Europe during the Middle Ages, from the Eight Century to 1340, Woodbridge, The Boydell Press, 1997 (orig. holandés 1954).

Wagner, Kay, “Debellare Albigenses”. Darstellung und Deutung des Albigenserkreuzzuges in der europäischen Geschichtsschreibung von 1209 bis 1328, Neuried, 2000 (Politik im Mittelalter, 4).

WAGNER, Kay, Les sources de l'historiographie occidentale de la Croisade albigeoise entre 1209 et 1328, en Roquebert (dir.), La Croisade albigeoise, pp. 39-54.

Wise, Terence; Scollins, Richard, The Knights of Christ, Londres, Osprey Publishing, 1984 (Osprey Men-at-Arms, 155). 